\title{
Prediction of Cracking in Reinforced Concrete Structures
}

Nicholas J. Carino

Structures Division

and

James R. Clifton

Building Materials Division

April 1995

Building and Fire Research Laboratory

National Institute of Standards and Technology

Gaithersburg, MD 20899

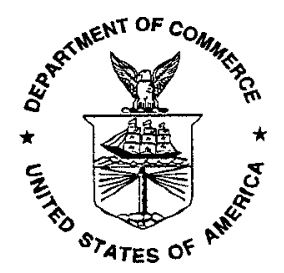

U.S. Department of Commerce

Ronald H. Brown, Secretary

Technology Administration

Mary L. Good, Under Secretary for Technology

National Institute of Standards and Technology

Arati Prabhakar, Director 


\begin{abstract}
The useful life of a buried concrete, containment structure for low level nuclear waste may be controlled by the loss of its load-bearing capacity or an increase in permeability. The latter factor is controlled by the general degradation of the concrete and by the presence of discrete cracks resulting from externally applied loads or from restraint to normal volume changes. To be able to predict the effects of cracks on permeability, it is necessary to understand the causes and mechanisms of discrete crack formation in reinforced concrete structures. The objective of this report is to provide an overview of the design and behavior of reinforced concrete members and to discuss the factors affecting the formation of cracks in hardened concrete. The underlying philosophy of modern reinforced concrete design is presented, and it is shown that it allows for the formation of cracks of controlled widths under service loads. Models for predicting the width of flexural cracks are reviewed. Factors affecting drying shrinkage cracks and approximate methods for considering them are discussed. An example is provided to illustrate how to determine whether drying shrinkage cracks will develop under specific conditions. This is followed by a discussion of techniques to predict the number and widths of drying shrinkage cracks. Finally, there is a discussion of the interaction between flexural and drying shrinkage cracking. The report is directed to the general audience who is unfamiliar with the structural aspects of reinforced concrete.
\end{abstract}

Keywords: building technology; concrete; cracking; creep; reinforced concrete; restrained shrinkage 


\section{TABLE OF CONTENTS}

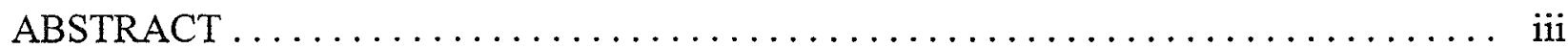

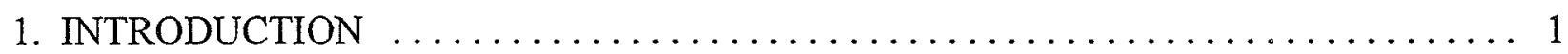

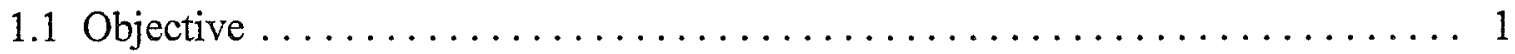

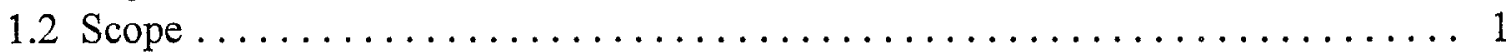

2. PRINCIPLES OF REINFORCED CONCRETE BEHAVIOR $\ldots \ldots \ldots \ldots \ldots \ldots \ldots$

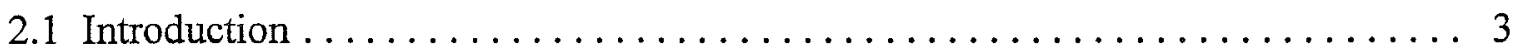

2.2 Reinforced Concrete Design Methodology . . . . . . . . . . . . . . . 3

2.3 Flexural Behavior ..................................... 5

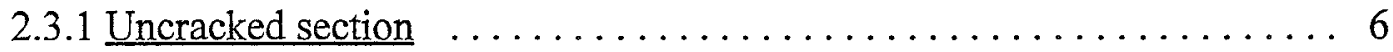

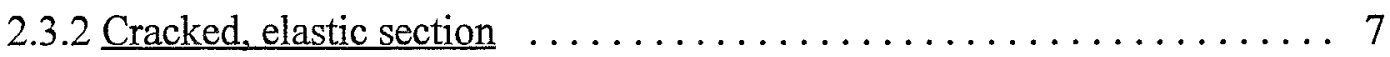

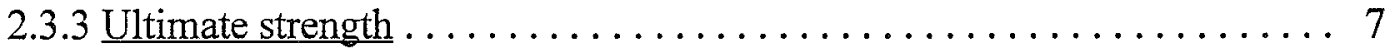

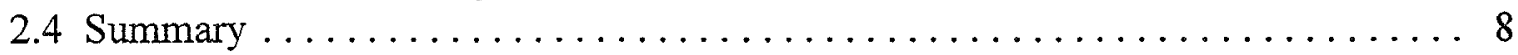

3. CONTROL OF WIDTH AND SPACING OF FLEXURAL CRACKS $\ldots \ldots \ldots \ldots \ldots 11$

3.1 ACI Approach ...................................... 11

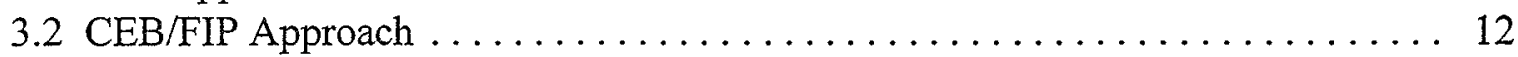

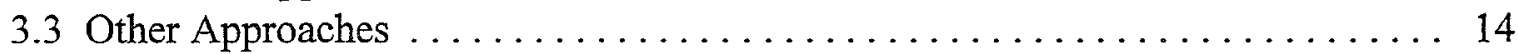

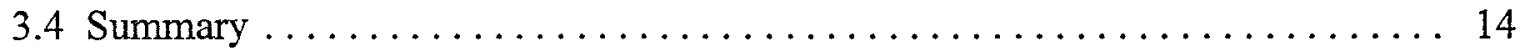

4. RESTRAINED SHRINKAGE CRACKING $\ldots \ldots \ldots \ldots \ldots \ldots \ldots \ldots \ldots \ldots \ldots \ldots \ldots \ldots \ldots$

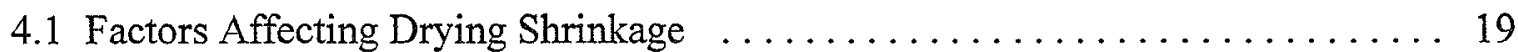

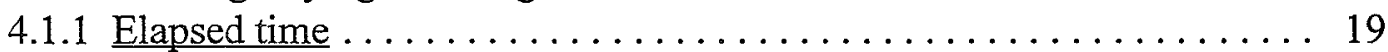

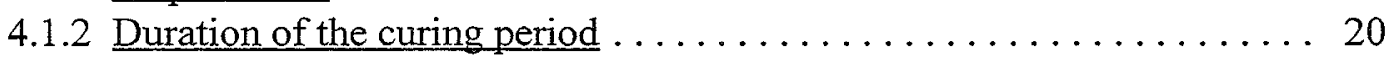

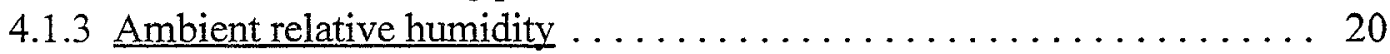

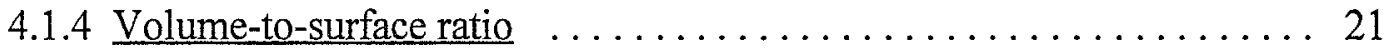

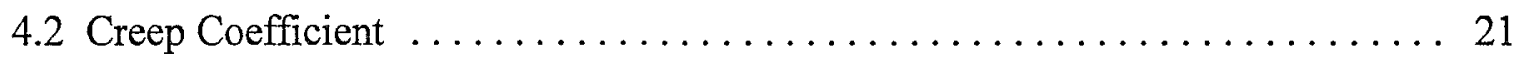

4.2 .1 Correction factors $\ldots \ldots \ldots \ldots \ldots \ldots \ldots \ldots \ldots \ldots \ldots \ldots \ldots \ldots \ldots \ldots, 22$

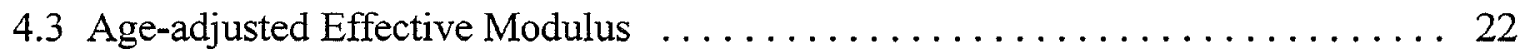

4.4 Prediction of Cracking due to Restrained Shrinkage $\ldots \ldots \ldots \ldots \ldots \ldots \ldots 23$

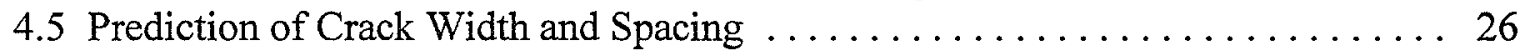

4.6 Interaction of Flexural and Drying Shrinkage Cracking $\ldots \ldots \ldots \ldots \ldots \ldots, 30$

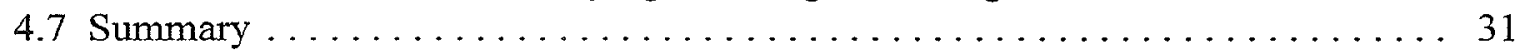

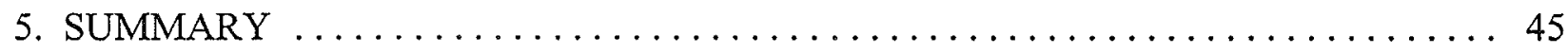

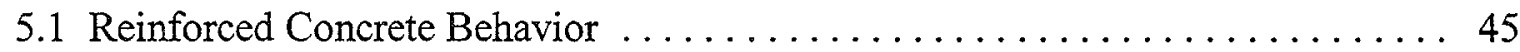

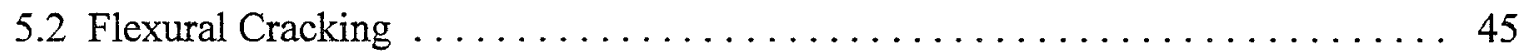

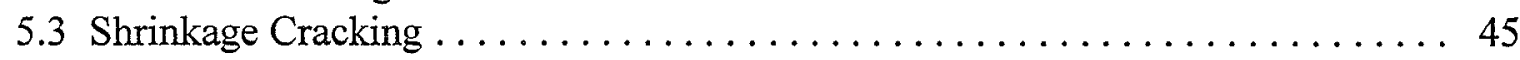

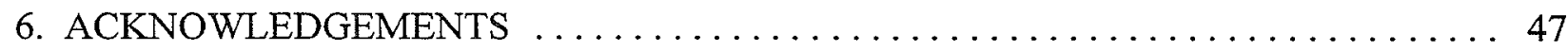

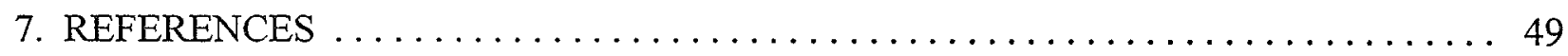




\section{INTRODUCTION}

\subsection{Objective}

The National Institute of Standards and Technology (NIST) is assisting the Nuclear Regulatory Commission (NRC) in the development of the technical bases for making assessments of the design and construction of low level nuclear waste (LLW) disposal facilities. The goal of the NIST work is to develop a computer-based system to predict the service life of underground concrete vaults, which could be used to evaluate the design of a specific facility.

In developing such a system, it is recognized that the end-of-life (EOL) of a concrete containment can result from one of two conditions: (1) loss of load-bearing capacity; or (2) increase in permeability of the concrete so that an unacceptable flow of water can occur through the structure. Loss of load-bearing capacity can occur because of deterioration of the concrete and the attendant loss in strength, or because of corrosion of the reinforcement. Corrosion damage can be in the form of reduction in cross-sectional area of the reinforcing bars or in loss of bar anchorage due to surface spalling. Loss of anchorage means that reinforcing bars are not able to develop their useable strength. Increased permeability can occur because of degradation mechanisms that affect the overall integrity of the concrete, such as sulfate attack or alkali-aggregate reactivity, or it can occur due to the formation of discrete structural cracks. To be able to predict the effects of structural cracks on permeability, it is necessary to understand the causes and mechanisms of discrete crack formation in reinforced concrete structures.

The objective of this report is to provide an overview of the design principles and the behavior of reinforced concrete members subjected to bending. Factors affecting the formation of cracks due to externally applied loads or due to restraints against drying shrinkage are discussed. The report is directed primarily to the general reader in need of working information on the structural behavior and the cracking of reinforced concrete. The reader, however, is assumed to be familiar with the basic concepts of mechanics of materials.

\subsection{Scope}

Chapter 2 presents the principles of reinforced concrete design and describes the behavior of a reinforced concrete beam due to an increasing bending moment, as would arise from the application of transverse loads. It will be shown that flexural cracks are normally expected during the service life of a safely-designed, ordinary, reinforced concrete structure. However, similar types and sizes of cracks may not be acceptable in a specialized structure such as a nuclear waste containment vessel.

Chapter 3 discusses the factors affecting the characteristics of flexural cracks that develop under service loads. Different approaches for predicting crack widths are discussed, and the methods that a designer can use to control crack widths are mentioned. 
Chapter 4 deals with the problem of cracking when there is restraint to drying shrinkage. The factors affecting the magnitude of drying shrinkage in a specific member are reviewed. The complexities involved in predicting the formation of drying shrinkage cracks when there is restraint to shrinkage are discussed. An example is used to illustrate the application of design methods to determine whether cracking will occur under a given set of conditions. Methods to estimate the number and magnitude of drying shrinkage cracks are highlighted, and the interaction of flexural and shrinkage-induced cracks is discussed.

Chapter 5 provides a summary of the report. 


\section{PRINCIPLES OF REINFORCED CONCRETE BEHAVIOR}

\subsection{Introduction}

The tensile strength of concrete is about 10 percent of the compressive strength, but in the design of reinforced concrete structural elements, this strength is neglected. Steel reinforcement is provided to carry the tensile stresses in a member due to applied loads. It is expected that cracks will develop in a reinforced concrete member under service loads (the expected loads during the lifetime of the structure). However, the designer has some control over the width and distribution of structural cracks.

In addition to cracks resulting from external loads, cracks can also result from restrained volume change. When concrete drys, it shrinks. If the shrinkage is restrained, tensile stresses develop. If the stresses exceed the tensile strength of the concrete, cracks develop. Restraint can be provided by connection to other elements which do not undergo the same amount of shrinkage, or it can arise because of non-uniform drying throughout the member.

Concrete under stress (or deformation) experiences creep (or stress relaxation). Creep refers to an increase in deformation under constant stress, and stress relaxation refers to a decrease in stress under constant deformation. Because of the complex interactions between drying shrinkage and stress relaxation, it is difficult to predict reliably whether cracks will occur as a result of drying shrinkage. In design practice, the formation of shrinkage induced cracks is controlled by providing a prescribed amount of reinforcement, often called temperature and shrinkage steel. Note that the term control does not mean eliminate. The temperature and shrinkage steel does not prevent shrinkage cracking, but it controls the width and spacing of the cracks that form, so that they do not interfere with the serviceability of the structure.

This chapter discusses the mechanics of the formation of cracks in structural members and presents methods for predicting expected crack widths under service loads. Two cracking cases are considered: (1) flexural cracks that form when the tensile stresses due to bending ${ }^{1}$ exceed the flexural strength of the concrete; (2) direct tension cracks that form when there is restraint to drying shrinkage (and thermal contraction) and the induced tensile stresses exceed the strength of the concrete. A brief overview of the basic principles of reinforced concrete design is presented in the next section.

\subsection{Reinforced Concrete Design Methodology}

The methodology for designing reinforced concrete members is in a constant state of flux as more knowledge is gained about the structural performance of members made with new materials and constructions schemes. In the past, reinforced concrete members were designed by the elastic or working stress methods, analogous to the methods that were used to design steel structures. In

\footnotetext{
${ }^{1}$ The quantitative measure of the action causing a member to bend is called the bending moment and has the units of force distance, such as $\mathrm{N} \cdot \mathrm{m}$.
} 
this approach, structures were designed so that the maximum expected stresses under service loads would be a fraction of the strengths of the concrete and steel.

Beginning in the 1950s, the concept of strength design started to gain in acceptance (Winter and Nilson 1979), and it eventually replaced the elastic design method. In this approach, a structural element is proportioned so that it will fail under an overload condition that has a low probability of occurring. Member strengths are calculated by accounting for the actual non-linear stress strain ${ }^{2}$ behavior of the concrete and steel which precedes failure.

In symbolic terms, strength design satisfies the following equation (Winter and Nilson 1979)

$$
\phi S_{n} \geq \sum \psi_{i} L_{i}
$$

where $S_{n}=$ the nominal strength calculated from assumed material properties and a behavioral model,

$\phi=$ strength reduction factor to account for uncertainties in the calculated nominal strength,

$L_{i}=$ the $i t h$ of the service loads (dead load, live load, wind, etc.) acting simultaneously on the member, and

$\psi_{\mathrm{i}}=$ a load factor to account for the uncertainty in $L_{i}$.

The strength reduction factor, $\phi$, depends on the type of structural action being considered (bending, axial load, shear, etc.) and the type of member. The load factors, $\Psi_{i}$, depend on the uncertainties of the loads. Because the magnitudes of live loads are more uncertain than those of dead loads, the load factor for live load is larger than that for dead load. The ACI Code (ACI 318-89) stipulates values of the strength reduction and load factors. For example, the $\phi$-factor for flexure is 0.9 , the load factor for dead load is 1.4, and the load factor for live load is 1.7. Structures designed according to the ACI Code are intended to have a probability of failure of the order of $10^{-5}$ (Winter and Nilson 1979). If the designer desires a lower failure probability for a particular member, a lower $\phi$-factor or higher load factors could be used to proportion that member.

A member designed according to the strength design method is proportioned so that it will attain its ultimate strength under a specified overload condition, which is referred to as the ultimate limit state. This assures that the structure will have an adequate margin of safety under the service loads. However, a safe structure does not necessarily mean that it will serve its intended function. Hence, after the structure is designed for adequate safety, it is checked to assure adequate performance under service loads, referred to as the serviceability limit states. Typically, the designer checks to assure that deflections are within acceptable limits and that crack widths are acceptable for the intended function or environmental exposure. For certain specialized structures, such as sanitary structures that must retain water, the serviceability limit state (that is, crack width) may control the design and larger load factors are used compared with ordinary structures designed according to ACI 318 (Klein, Hoffman and Rice 1982).

${ }^{2}$ Stress refers to load per unit area, and strain refers to change in length per unit length. Strain is a dimensionless quantity. 
With this brief introduction to the general design concepts for reinforced concrete members, the cracking behavior of a reinforced concrete beam is examined.

\subsection{Flexural Behavior}

Reinforced concrete elements are designed to carry three type of loads, namely, axial force, bending moment, and shearing force. Axial compressive loads are associated with columns, piles, and foundation walls, and tensile forces may be introduced into members as a result of restrained shrinkage. Bending moments occur in a member supported at discrete points and subjected to loads that are transverse to the longitudinal axis of the member. Shearing forces arise from transverse loads or from torsional moments. In designing a member to assure adequate safety, the engineer considers all the foreseeable loads that may occur during the service life of the structure.

To gain an understanding of the cracking expected under service loads, the flexural behavior of a reinforced concrete member is discussed. Figure 2.1(a) is a side view of a segment of a beam subjected to a constant bending moment (pure bending). For the direction of the bending moment shown in the figure, the top half of the beam is subjected to compression and the bottom half is subjected to tension. There is a plane in the beam which is not strained, and this is known as the neutral surface. The intersection of the neutral surface with a cross section defines the neutral axis. A fundamental assumption of bending theory is that plane sections remain plane ${ }^{3}$. Thus the ends of the beam remain plane under the action of the bending moment, and this results in a linear variation of strain with distance from the neutral axis (Timoshenko and Gere 1972). Figure 2.1(b) shows the linear strain distribution over the depth of the beam. The maximum compressive strain, $\epsilon_{c}$, occurs at the top surface of the beam, and the maximum tensile strain, $\epsilon_{t}$, occurs at the bottom surface. If the beam is made of a linear-elastic material, that is, a material for which stress is proportional to strain, there is also a linear stress distribution over the depth of the beam, as shown in Fig. 2.1(c).

The assumption of a linear strain distribution is fundamental in analyzing the behavior of a reinforced concrete beam as the bending moment is increased up to the ultimate strength of the beam. This assumption along with the stress-strain curves of the concrete and steel permit determination of the stress distribution in the beam. Figure 2.2 shows schematic stress-strain curves of concrete and steel that are assumed for the design of reinforced concrete members. The compressive stress-strain curve for concrete is not unique but depends on the testing conditions and the nature and proportions of the materials that make up the concrete. There is no well-defined elastic limit and the curve deviates from a straight line in a gradual fashion. The usual design assumption is that the stress-strain curve is linear up 50\% of the short-term, compressive strength (designated as $f_{c}^{\prime}$ in Fig. 2.2(a)).

In design, it is often assumed that concrete fails in compression when it reaches a compressive strain of 0.003 . Compressive failure occurs by formation of cracks parallel to the loading direction,

${ }^{3}$ Transverse planes of a beam which are flat before any load is applied remain flat after the bending moment is applied, that is, they simply rotate slightly but they do not distort. 
and is referred to as splitting failure. The steel is assumed to have a linear stress-strain relation until the yield stress, $f_{y}$, is attained. After the yield stress is attained, it is assumed that the stress in the steel remains constant as the strain increases, that is, strain hardening is neglected. The steel tensile strain corresponding to the onset of yielding is $\epsilon_{y}$.

With the above assumptions, it is now possible to follow the progression of flexural cracking as the bending moment on a reinforced concrete beam is increased. There are three principal stages of behavior to consider:

(1) the beam is uncracked

(2) the beam is cracked, but stresses are within the elastic range

(3) the beam reaches its ultimate strength

\subsubsection{Uncracked section}

Figure 2.3(a) shows a rectangular reinforced concrete beam subjected to a bending moment. The total area of reinforcing bars at a distance $d^{4}$ from the compression face is $A_{s}$. It assumed that there is complete bond between the concrete and steel, which means that the steel and concrete experience the same strain. Provided the maximum tensile stress in the concrete is less than the modulus of rupture (the maximum tensile stress at cracking of an unreinforced concrete beam), the entire section of the beam acts to resist the bending moment. The tensile stress in the steel bars is greater than the tensile stress in the concrete at the same depth because the steel has a larger modulus of elasticity (ratio of stress to strain in the elastic range). Since the steel and concrete experience the same strain, the ratio of stresses equals the modular ratio, $n$, which is the ratio of the modulus of elasticity of the steel to that of the concrete. For ordinary strength concrete, this ratio is approximately 8 . For the purpose of analysis, the steel bars can be replaced by an area of concrete equal to $n A_{s}$, which allows the composite beam to be represented as an equivalent beam made entirely of concrete. The elastic bending formula can be used to calculate the maximum compression and tensile stresses, $f$, in the concrete:

$$
f=\frac{M y}{I_{u t}}
$$

In Eq. (2.2), $y$ is the distance from the neutral axis to the extreme face of the beam, and $I_{u t}$ is the moment of inertia ${ }^{5}$ of the uncracked transformed cross section about the neutral axis. Figure 2.3(a) shows the strain and stress distribution in the beam during this stage. The stress in the steel is $n$ times the stress computed using the bending formula, with a value of $y$ equal to the distance from the neutral axis to the depth of the steel.

${ }^{4}$ Distance is measured from the compression face to the center, or centroid, of the bars.

${ }^{5}$ The moment of inertia of the cross section is given by the integral $\int y^{2} d A$ and is a measure of the efficiency of the cross section in resisting bending. The distance $y$ is measured from the neutral axis to the differential area, $d A$, of the cross section. 


\subsubsection{Cracked, elastic section}

When the maximum tensile stress in the uncracked beam reaches the modulus of rupture, the concrete cracks. Cracks are assumed to extend from the tension face to the neutral surface, which is the same as assuming that the concrete below the neutral surface has zero tensile strength. After cracking, it is still assumed that plane sections remain plane, so that there is still a linear strain distribution through the depth of the beam. For analysis, the steel is replaced by an equivalent area of concrete equal to $n A_{s}$, so that the cracked transformed section is as shown in Fig. 2.3(b).

When the crack develops, there is a sudden increase in the maximum stresses in the concrete and steel. However, for a properly designed beam these stresses will remain within the elastic ranges. The stress distribution in the concrete is as shown in Fig. 2.3(b). The compressive stresses in the concrete can be replaced by an equivalent compressive force, $C$, passing through the centroid of the triangular stress distribution, and the stresses in the steel can be replaced by a tensile force, $T$, acting at the center of the steel. Equilibrium of forces requires that $\mathrm{C}=\mathrm{T}$, which establishes the depth of the neutral axis, $k d$, and the depth of the crack. Another equilibrium condition, $\mathrm{M}=j d \mathrm{~T}=j d \mathrm{C}$, establishes the relationship between the bending moment and the maximum stresses in the steel and concrete. Under service loads, normally designed flexural members will be in this cracked, elastic condition. The maximum stresses in the concrete and steel at a particular cross section will depend on the bending moment produced by the applied loads. In actual structures, the bending moment varies along the length of a beam, and so the maximum stresses in the concrete and steel will also vary along the length. In addition, for beams (or slabs) that are continuous over one or more supports, the direction of the bending moment changes in the vicinity of the support. As a result, cracking can also exist on the top face of a continuous beam.

As the bending moment increases above the cracking moment, the neutral axis remains at the same location, $k d$, provided that the maximum compressive stress in the concrete is within the linearelastic range and the steel stress is less than $f_{y}$. When the concrete stress goes beyond the linearelastic range, the neutral axis moves toward the compression face. However, the strain distribution through the depth is still assumed to be linear. As a consequence, the stress distribution in the concrete looks like the portion of the stress-strain curve up to the strain corresponding to the maximum strain on the compression face.

\subsubsection{Ultimate strength}

As the bending moment is increased further, the neutral axis moves further toward the compressive face. In a properly designed member, the next key stage is yielding of the steel. This occurs when the strain at the level of the steel reaches $\epsilon_{y}$. The bending moment can be increased further ${ }^{6}$ until the maximum compressive strain in the concrete reaches the assumed limiting value of 0.003 . The strain distribution at failure is shown in Fig. 2.3(c). Because the steel has yielded, the steel stress is $f_{y}$, and the steel provides a tensile force equal to $A_{s} f_{y}$. The tensile force is balanced by an equivalent compressive force in the concrete, which acts through the centroid of the concrete

${ }^{6}$ While the values of $\mathrm{C}$ and $\mathrm{T}$ can not increase above $A_{s} f_{y}$, the distance between $\mathrm{C}$ and $\mathrm{T}$ can increase, and this results in a small increase in bending moment capacity. 
stress distribution. The balance of forces establishes the location of the neutral axis, $c$, and the ultimate moment equals $A_{s} f_{y} z$, where $z$ is the distance between the tensile and compressive forces. At this stage, the concrete undergoes compressive failure and the beam is no longer able to the support the applied moment.

\subsection{Summary}

This chapter has provided an overview of the principles of design and behavior of reinforced concrete. Reinforced concrete structures are designed to fail under an overload condition that has a small probability of being exceeded during the service life. After a structure is designed for safety, it is checked to assure that it will perform in a satisfactory manner under service conditions. The serviceability checks usually involve assuring that deflections and crack widths satisfy appropriate criteria for the intended use.

The essential features of the mechanics of a reinforced concrete beam under the action of a bending moment have been discussed. The beam will crack under service loads if the tensile stress in the concrete exceeds the bending strength of plain concrete. After formation of cracks, the steel carries the tensile force needed to support the applied load. The cracked beam can continue to support increasing loads until the ultimate capacity is attained due to compression failure of the concrete.

The next chapter takes a closer look at the flexural cracks that form under service loads and discusses how the designer can control their widths. 


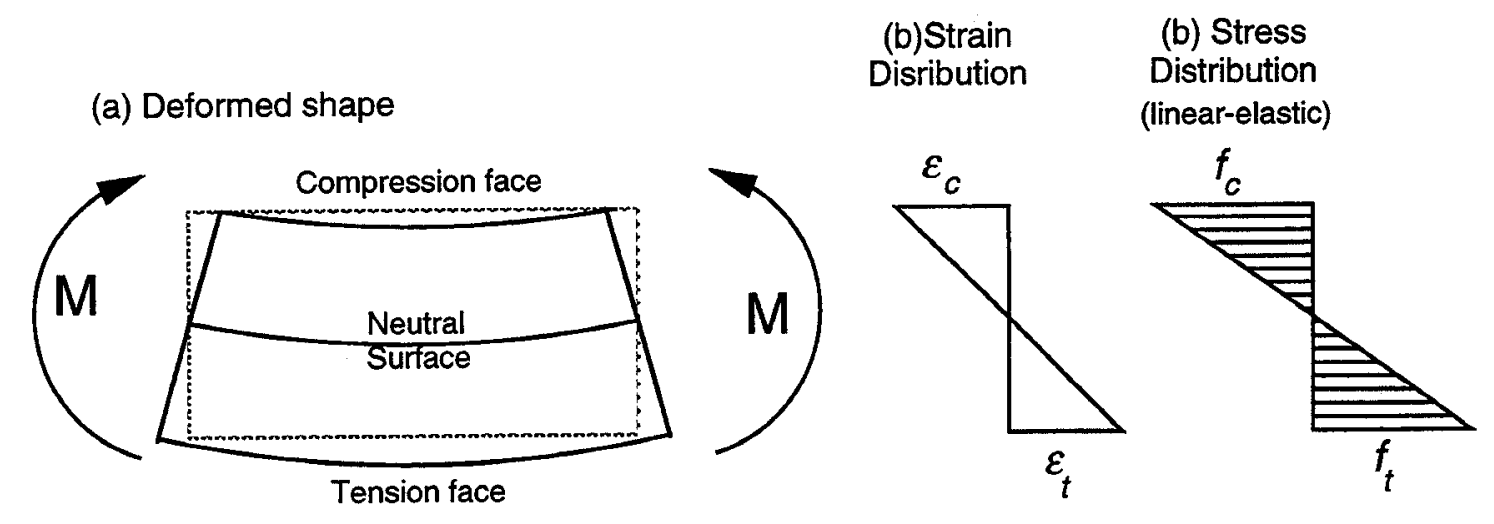

Figure 2.1 - Pure bending of a beam
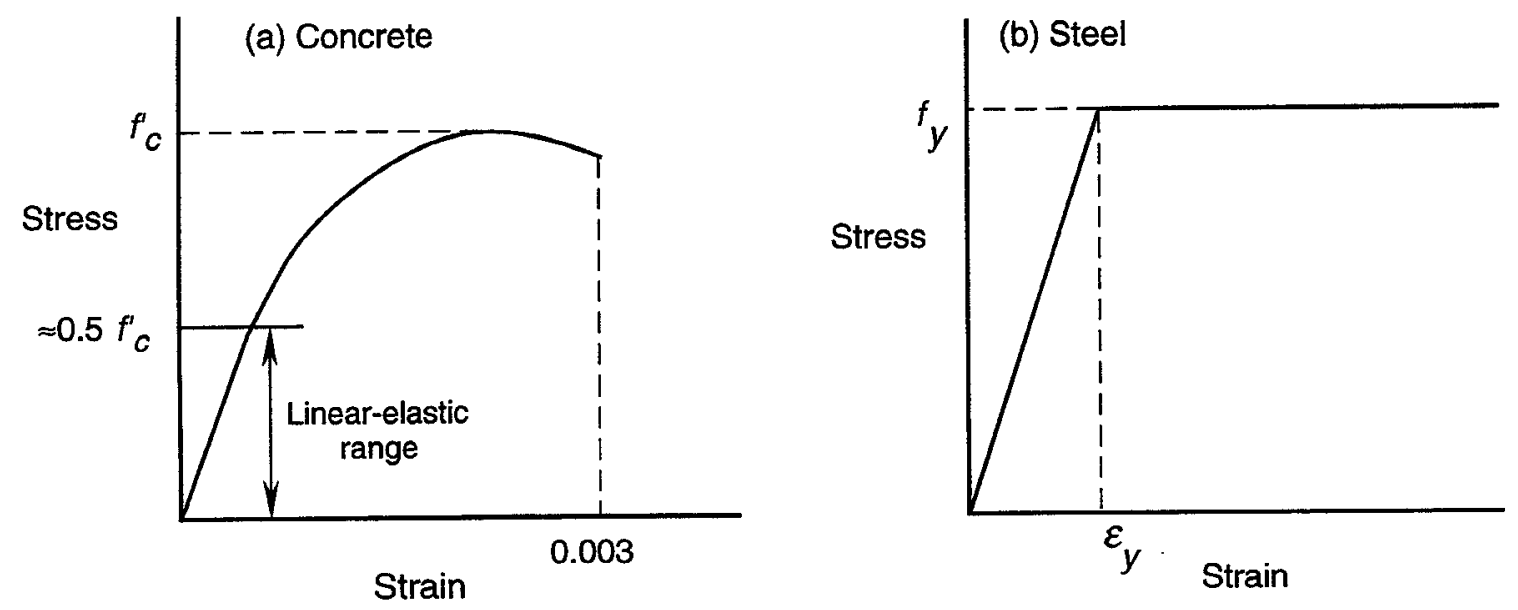

Figure 2.2 - Schematic stress-strain curves of concrete and steel 
(a) Uncracked behavior

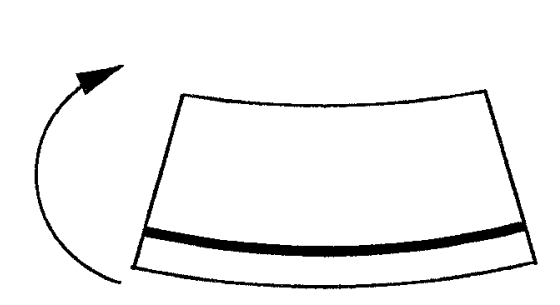

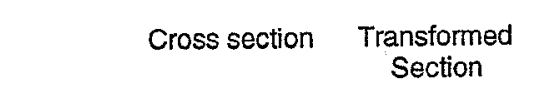

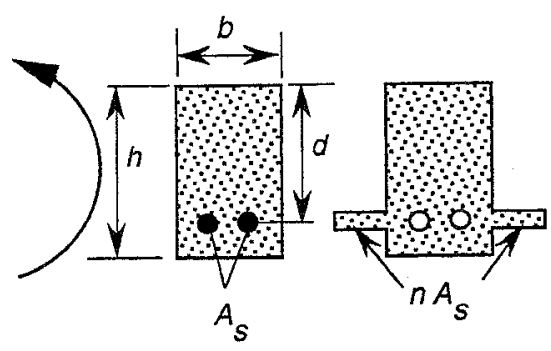

(b) Cracked, elastic behavior
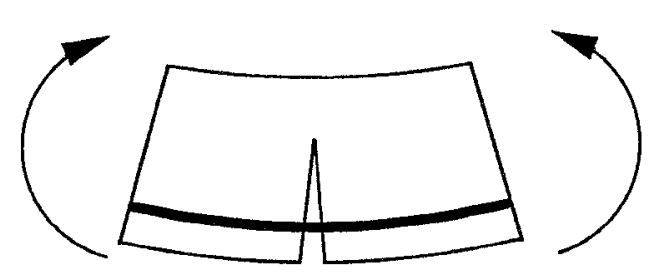
Transformed Section

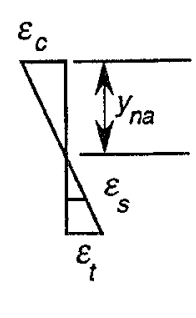

Strain
Distribution
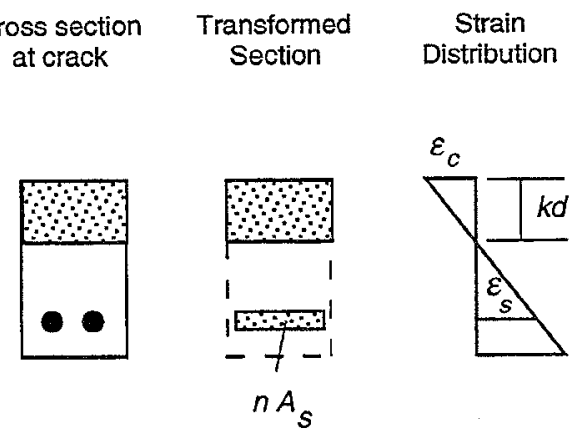

Stress

Distribution

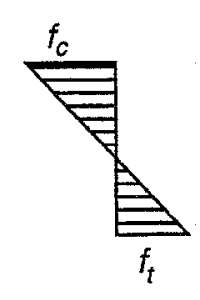

(c) Ultimate strength condition

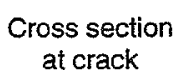

Stress
Distribution

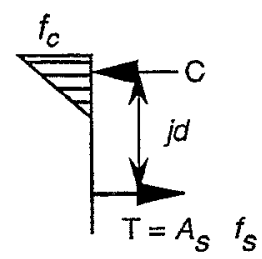

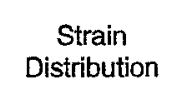

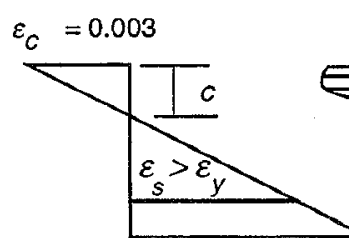

Stress Distribution
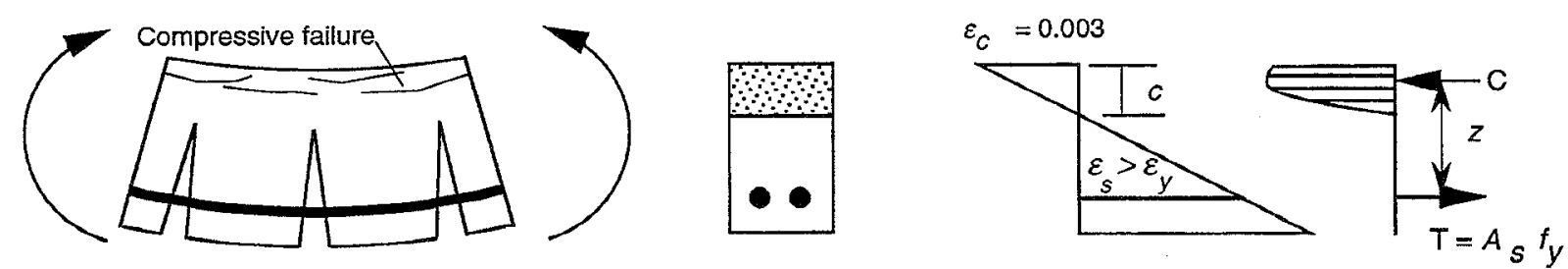

Figure $2.3-$ Behavior of a reinforced concrete beam with increasing bending moment 


\section{CONTROL OF WIDTH AND SPACING OF FLEXURAL CRACKS}

\subsection{ACI Approach}

The discussion in the previous chapter explained that flexural cracks develop in a beam when the applied bending moment exceeds the cracking moment of the uncracked, transformed section. The flexural crack that forms at a cross section is assumed to extend from the tension face to the neutral axis. Provided the concrete and steel stresses are within the elastic range, the location of the neutral axis depends primarily on the amount of reinforcing steel. An increase in the area of steel reduces the distance from the tension face to the neutral axis, which reduces the depth of flexural cracks. However, the ACI Code (ACI 318-89) limits the amount of steel in the tension zone to assure that the steel yields before the concrete fails in compression. This limitation ensures that, in case of an overload condition, the beam will display noticeable deflections and cracking prior to failure, thereby providing warning that the beam is critically loaded.

While the formation of flexural cracks in a properly designed beam is not significant in terms of structural safety, it can affect the serviceability of the structure. Excessive crack widths can impair corrosion resistance of exposed structures. For a liquid retaining structure, excessive crack widths may result in leakage. Therefore, control of cracking may be critical for serviceability. The report of $\mathrm{ACI}$ Committee 224 ( $\mathrm{ACl} 224 \mathrm{R}-90$ ) provides the designer with basic information on the principles of crack control. In addition, the report of ACI Committee 350 (ACI 350-89) on environmental engineering structures, provides guidelines for achieving watertight concrete structures. Some of the key principles contained in these documents are summarized in this section.

Based on the analysis of measurements on beams, $\mathrm{ACl}$ Committee 224 arrived at the following conclusions about the factors affecting flexural crack widths (ACI 224R-90):

- The steel stress (or strain) is the most important variable affecting crack width.

- The thickness of the concrete which covers the reinforcing bars (called cover) and the crosssectional area of concrete surrounding each bar are important geometric variables.

- The crack width on the tension face is affected by the strain gradient from the level of the steel to the tension face.

- The bar diameter is not a major variable.

To account for the major factors affecting crack width, ACI Committee 224 recommends the following flexural crack-width formula, which is based on the so-called Gergely-Lutz equation:

$$
w=2.2 \beta \epsilon_{s} \sqrt[3]{d_{c} A}
$$

where $w=$ most probable crack width (in.),

$\beta=$ ratio of distance between neutral axis and tension face to distance between neutral axis and centroid of reinforcing steel,

$\epsilon_{\mathrm{s}}=$ strain in reinforcement due to applied load,

$d_{c}=$ thickness of cover from tension face to center of closest bar (in.), and 


$$
\begin{aligned}
& A= \text { area of concrete symmetric with reinforcing steel divided by the number of bars (sq. } \\
& \text { in.). }
\end{aligned}
$$

Equation (3.1) is an empirically-based equation that was found to have good correlation with test data. Figure 3.1 illustrates the geometrical factors involved in this crack-width formula. For beams, the value of $\beta$ is approximately 1.2. The tensile strain in the steel, $\epsilon_{\mathrm{s}}$, is obtained by analyzing the cracked, elastic section (Fig. 2.3(b)) under the action of the service loads.

The ACI Code (ACI 318-89) does not include a formula to compute explicitly crack width under service loads. There is, however, a formula to calculate a $z$-value as follows:

$$
z=f_{s} \sqrt[3]{d_{c} A}
$$

where $f_{s}$ is the steel stress (ksi). The ACI Code places limits on the $z$-value as a means to control crack widths. This approach emphasizes the important influence of reinforcing details on the control of cracking, rather than the direct prediction of crack width, which is prone to uncertainty. From Eq. (3.2), it can be seen that crack control is achieved by reducing the steel stress under service loads, by using the least amount of concrete cover that is consistent with the environmental exposure, and by reducing $A$, the effective cross-sectional area of concrete surrounding each bar. The reduction of $A$ is achieved by having well-distributed reinforcement, that is, by using more smaller bars rather than fewer larger bars. The ACI Code does not consider the expected spacing between flexural cracks.

\subsection{CEB/FIP ${ }^{7}$ Approach}

The CEB/FIP Model Code 1990 (CEB 1990) for concrete structures uses an approach for crack control that differs from the ACI approach. The CEB/FIP technique considers the mechanism of stress transfer between the concrete and reinforcement to estimate crack width and spacing (see Hughes and Cifuentes 1988, or Beeby 1979 for further details on this mechanism). Figure 3.2 is a schematic of the tensile zone of a beam with a single reinforcing bar, and it serves to explain the CEB/FIP approach. Prior to cracking, tensile load applied to the beam causes equal strains in the concrete and steel. The strains increase with increasing load until the strain capacity of the concrete is reached, at which point cracks develop in the concrete, as indicated in Fig. 3.2(a). At the crack locations, the applied tensile load is resisted entirely by the steel. Adjacent to the cracks, there is slip between the concrete and steel, and this slip is the fundamental factor controlling the crack width. The slip causes transfer of some of the force in the steel to the concrete by means of interfacial stress (called bond stress) acting on the perimeter of the bar. Therefore, the concrete between the cracks participates in carrying the tensile force. The bond-slip mechanism causes the strains in the concrete and steel to have a periodic variation along the length of the member, as indicated schematically in Fig. 3.2(b) (CEB 1990, König and Tue 1992). At a crack, the steel strain is maximum and the

${ }^{7} \mathrm{CEB}$ stands for Comité Euro-International du Béton and FIP stands for Fédération Internationale de la Précontrainte. The former deals with reinforced concrete and the latter deals with prestressed concrete. 
concrete strain is zero. In between cracks, the steel strain is minimum and the concrete strain is maximum. If, under increasing load, the concrete strain reaches the limiting tensile strain, an intermediate crack forms between two previously formed cracks.

In the CEB/FIP approach, the crack width is related to the distance over which slip occurs and to the difference between the steel and concrete strains in the slip zones on either side of the crack. It is recognized that cracking is a probabilistic process, therefore, the estimated width is a characteristic crack width, having a low probability of being exceeded. The fundamental relationship to compute the characteristic crack width is as follows (CEB 1990):

$$
w_{k}=l_{s, \max }\left(\epsilon_{s m}-\epsilon_{c m}-\epsilon_{c s}\right)
$$

where $w_{k}=$ characteristic crack width,

$l_{s, \text { max }}=$ the maximum distance over which slip between the concrete and steel occurs;

$\epsilon_{s m}=$ average steel strain within $l_{s, \max }$,

$\epsilon_{c m}=$ average concrete strain within $l_{s, \max }$, and

$\epsilon_{c s}=$ concrete shrinkage strain (would be a negative value).

The approximate formula for $l_{s, \max }$ is as follows:

$$
l_{s, \max }=\frac{\phi}{3.6 \rho_{s, e f}}
$$

where $\phi=$ bar diameter and

$\rho_{s, e f}=$ area of steel divided by effective area of concrete in tension.

Equation (3.4) is based on the calculated distance from the crack plane that is required for the stress in the concrete to build up to the tensile strength of concrete due to bond stress (see Fig. 3.2(c)). In the CEB/FIP approach, the bond stress is assumed to be uniform over the slip distance and equal to 1.8 times the concrete tensile strength, $f_{i}$. The effective area of concrete surrounding each bar is similar to the $A$-value in the ACI approach (Eq. (3.1), although different methods are used in the CEB/FIP calculation (CEB 1990). According to this bond-slip model, intermediate cracks can occur only when the spacing between cracks exceeds $l_{s, \max }$. Thus crack spacing will range from $l_{s, \max }$ to 0.5 $l_{s, \max }$. The average crack spacing is taken to be approximately $2 / 3$ of $l_{s, \max }$.

To evaluate crack width according to Eq. (3.3), it is necessary to evaluate the difference between the average steel and average concrete strains within the slip zone. This difference is approximated by the following (CEB 1990):

$$
\epsilon_{s m}-\epsilon_{c m}=\epsilon_{s 2}-\beta \epsilon_{s r 2}
$$

where $\epsilon_{s 2}=$ steel strain at location of crack under service load,

$\epsilon_{s r 2}=$ steel strain at location of crack under load that causes cracking of the effective concrete area, and 


$$
\beta=\text { empirical factor to assess average strain within } l_{s, \max } \text { ( } \beta=0.6 \text { for short-term loading }
$$
and $\beta=0.38$ for long-term loading).

\subsection{Other Approaches}

The CEB/FIP approach presumes that crack width is governed by the relative slip between the concrete and steel. It has been argued that the slip mechanism is not the only one affecting crack width (Beeby 1979, Base 1976). If this were the case, there should be dramatic differences between the crack spacings in members with smooth bars compared with members with deformed bars (more slip with smooth bars). However, such differences have not been observed (Base 1976). Thus it has been suggested that surface crack width is also affected by strain release in the concrete surrounding the bar (Beeby 1979). This gives rise to the no-slip model for crack width, as shown in Fig. 3.3(a). In the no-slip model, the crack width is zero at the concrete-steel interface and increases with distance from the bar. The crack spacing for the no-slip mechanism is about two times the concrete cover distance. The width of real cracks is due likely to a combination of these two mechanisms, and some design codes try to accommodate this by using the following type of relationship to estimate average crack width (Beeby 1979):

$$
w_{m}=\left(K_{1} c+K_{2} \frac{\phi}{\rho}\right) \epsilon_{m}
$$

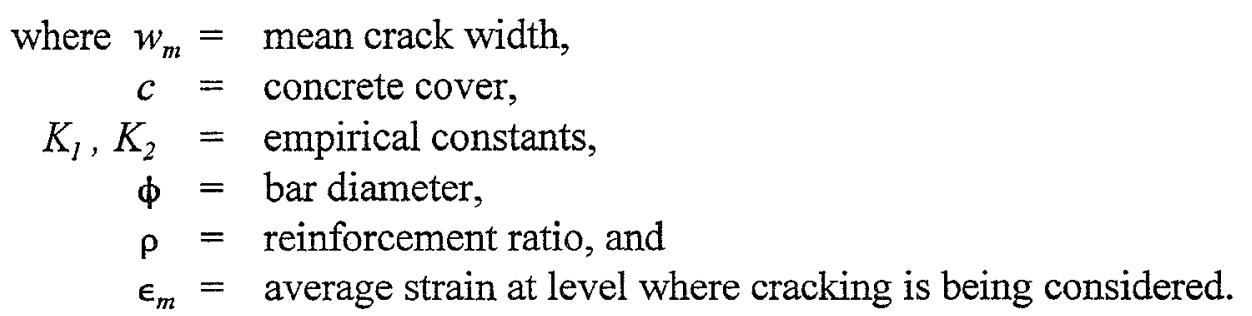

The above discussion has been for cracking in a member under direct tension. In a flexural member, the location of the neutral axis is another factor that contributes to surface crack width (Beeby 1979). Basically, because of the plane-sections-remain-plane approximation, the width of a flexural crack increases with the distance from the neutral axis (see Fig. 3.1 for a schematic representation of this concept). This geometric factor is taken into account in the ACI approach through the use of the $\beta$-value in Eq. (3.1).

\subsection{Summary}

Based on the foregoing discussion, it is seen that there are three major factors which contribute to the surface crack width in a reinforced concrete beam:

(1) strain release in the concrete in the vicinity of the crack;

(2) relative slip between concrete and steel; and

(3) distance from the neutral axis. 
Therefore, crack development in reinforced concrete elements is a complex process, and there is no universally accepted model for estimating crack width and crack spacing. Various design criteria have been proposed by different researchers (see Hughes and Cifuentes 1988). These have usually been simplified and subsequently incorporated into national codes. Some of the code equations are based upon classical models, such as the bond-slip mechanism used in the CEB/FIP approach, and others, such as the $\mathrm{ACI}$ approach, are based on empirical equations obtained by regression analysis of test data. It has been shown that the use of various code equations to estimate crack width in the same member can result in widely different values (Beeby 1979).

While there is no agreement on the most appropriate model to predict width and spacing of flexural cracks, there is agreement on the major factors affecting crack width. The most influential factor is the tensile strain in the steel under the action of the service loads. In structures where the control of crack width is of paramount importance, the critical design parameter may be the steel stress under service loads, rather than the ultimate strength of the member. The designer, can further reduce crack width by proper distribution of the reinforcement, that is, by using more smaller bars to provide the required steel area.

Various technical bodies have recommended tolerable crack widths for different exposure conditions. Some of these recommendations are given in Table 3.1. These values refer to the surface flexural crack widths computed by the specific crack-width formula adopted by that body. 
Table 3.1 - Tolerable crack widths

\begin{tabular}{|c|c|}
\hline Exposure condition & Tolerable crack width (mm) \\
\hline \multicolumn{2}{|l|}{ ACI 224R.90 } \\
\hline $\begin{array}{l}\text { Dry air or protective membrane } \\
\text { Humidity, moist air, soil } \\
\text { Deicing chemicals } \\
\text { Seawater and seawater spray; wetting and } \\
\text { drying } \\
\text { Water retaining structures }\end{array}$ & $\begin{array}{l}0.41 \\
0.30 \\
0.18 \\
\\
0.25 \\
0.10\end{array}$ \\
\hline \multicolumn{2}{|l|}{ ACI $318-89$} \\
\hline $\begin{array}{l}\text { Interior } \\
\text { Exterior }\end{array}$ & $\begin{array}{l}0.41 \\
0.33\end{array}$ \\
\hline \multicolumn{2}{|l|}{ ACI 350R-89 } \\
\hline $\begin{array}{l}\text { Normal* } \\
\text { Severe }\end{array}$ & $\begin{array}{l}0.27 \\
0.22\end{array}$ \\
\hline \multicolumn{2}{|c|}{ CEB/FIP Model Code 1990} \\
\hline Humid environment, deicing agents, seawater & 0.30 \\
\hline
\end{tabular}

*Normal sanitary exposure is defined as liquid retention (watertight) when exposed to liquids with $\mathrm{pH}>5$ or exposed to sulfate solutions less than $1500 \mathrm{ppm}$. 

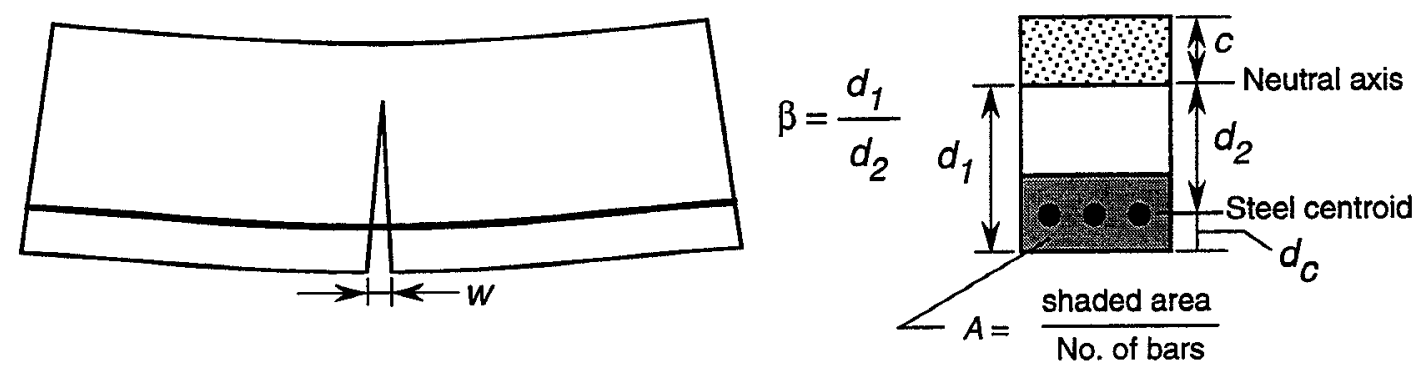

Figure 3.1 - Geometrical factors in the ACI approach for control of flexural crack width

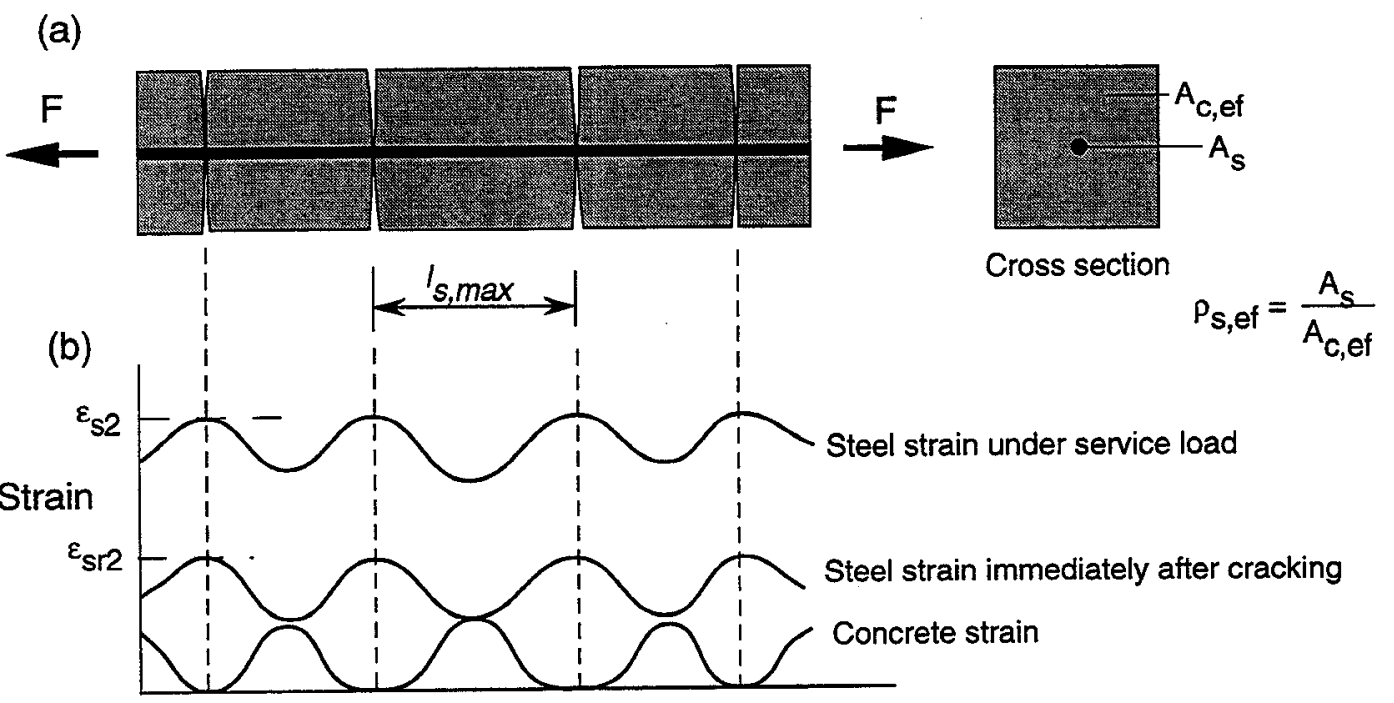

Position

(c)

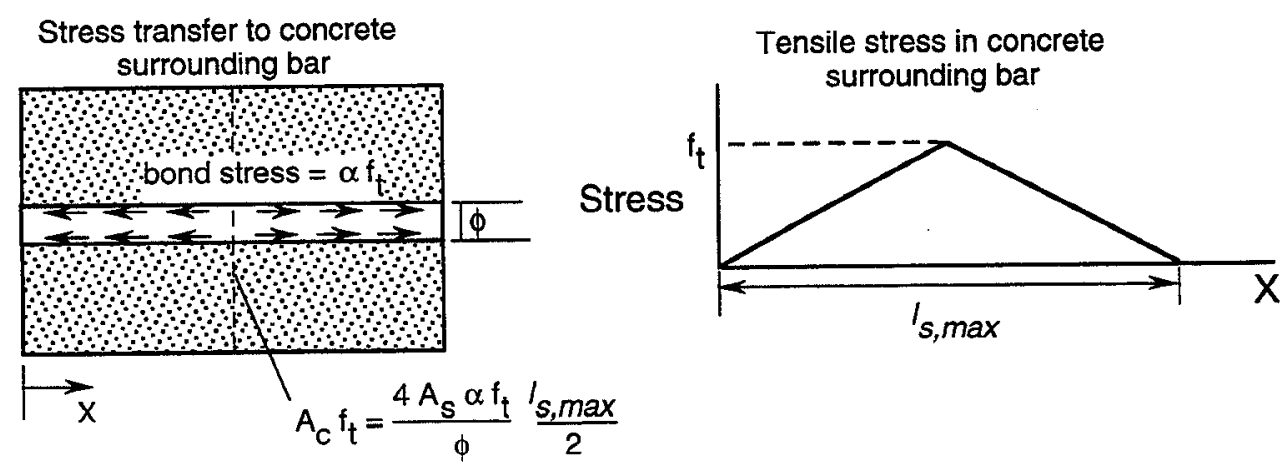

Figure 3.2 - (a) Multiple cracks in tensile zone of a member; (b) schematic of strain variation along length of member according to bond-slip model; and (c) model for computing slip length 


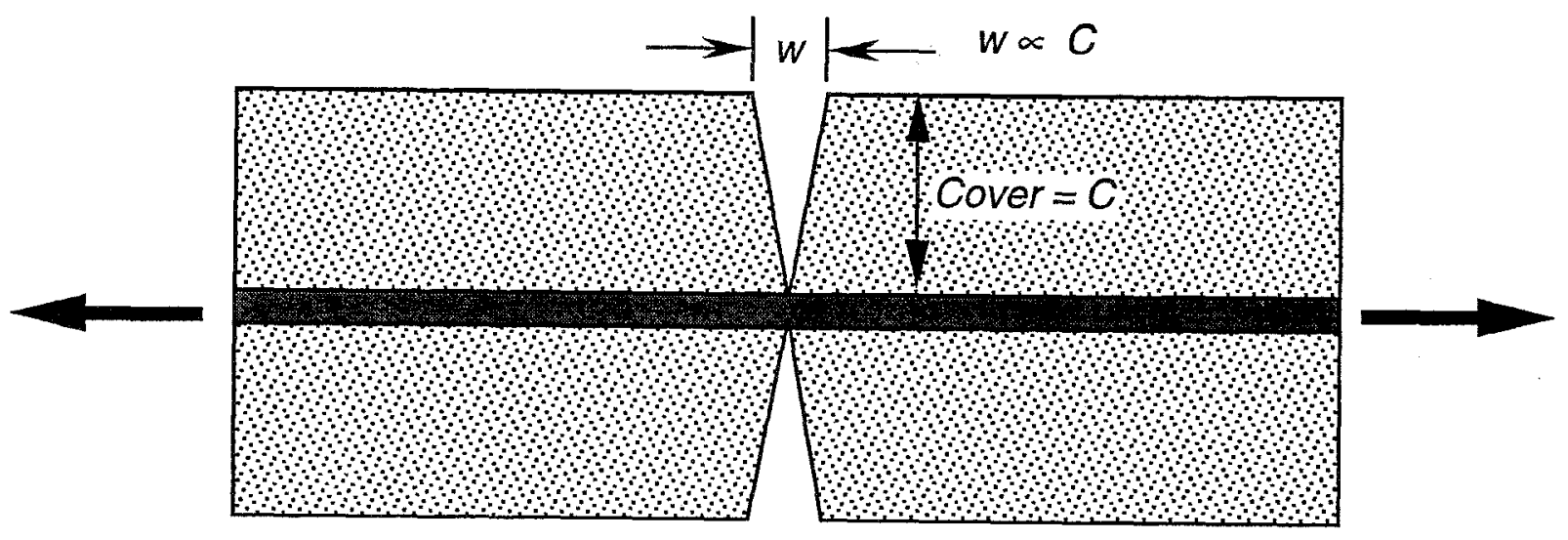

(a) No-slip model

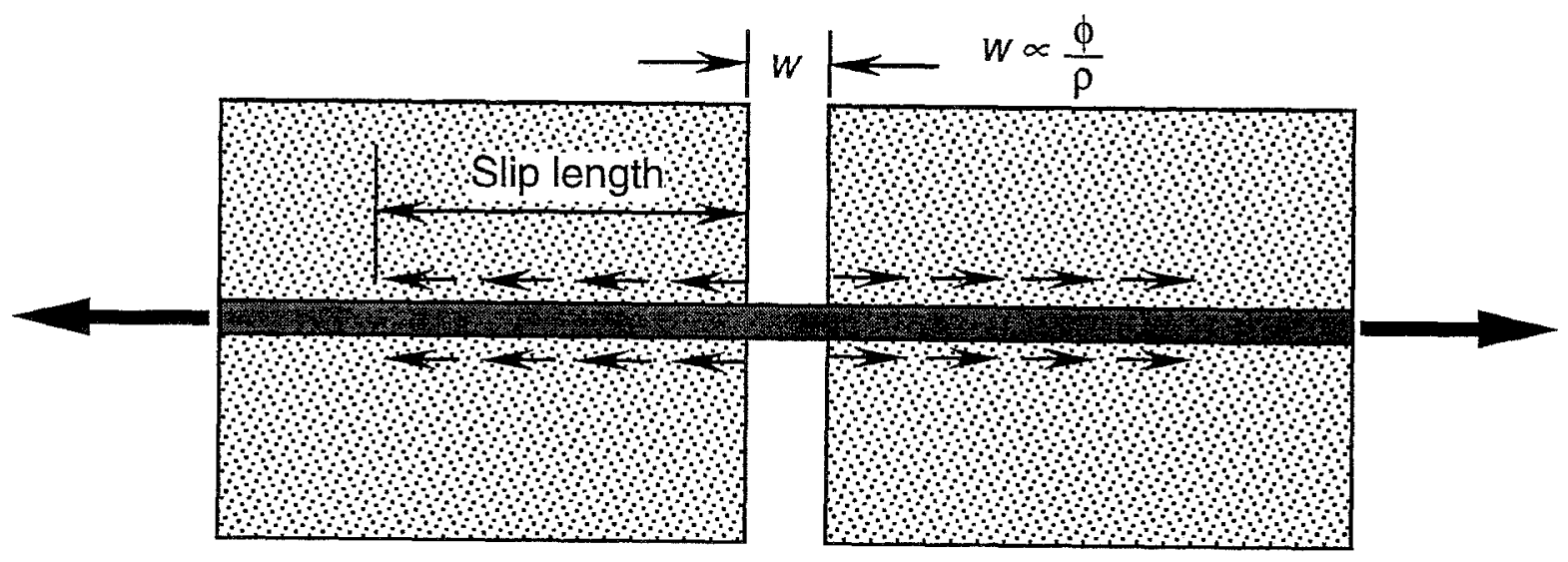

(b) Bond-slip model

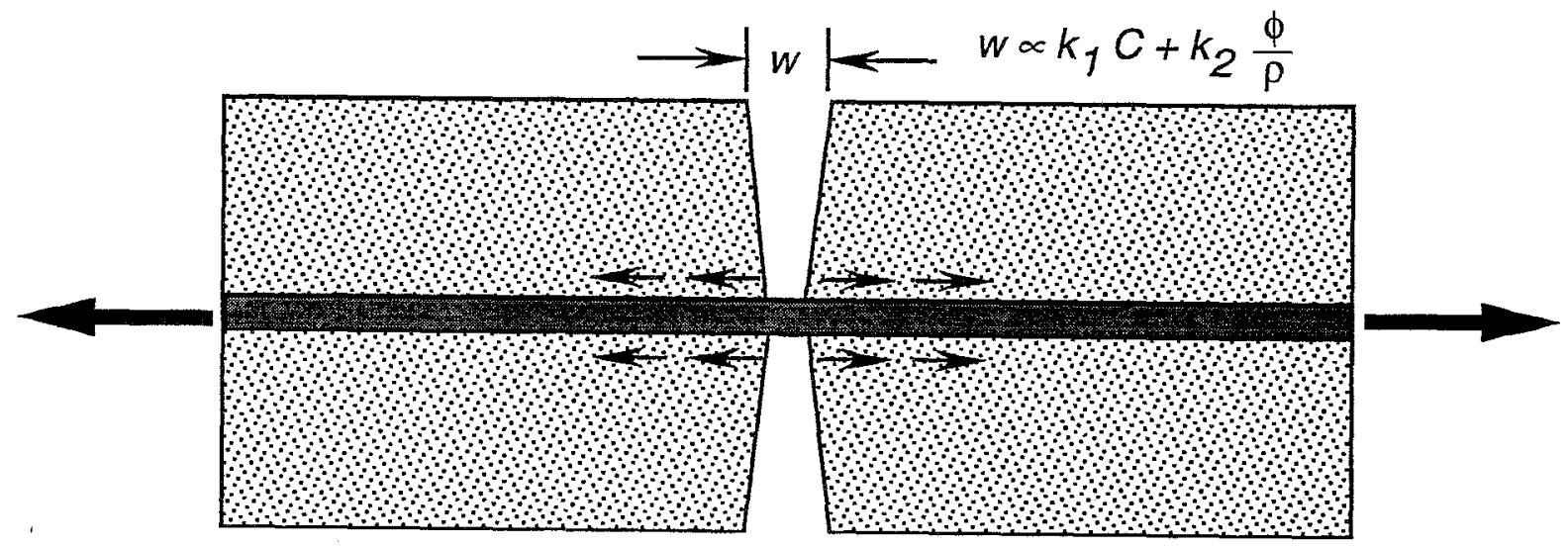

(c) Combined model

Figure 3.3 - Comparison of crack width models 


\section{RESTRAINED SHRINKAGE CRACKING}

The previous chapters have dealt with the formation of flexural cracks in reinforced concrete members. From a practical point of view, the major detrimental effects of flexural cracks are to increase the susceptibility of reinforcement to localized corrosion and to increase deflections under service loads. Because flexural cracks under service loads extend only to the depth of the neutral axis, they generally will not have a drastic effect on the permeability through the depth of a member. However, there is another source of cracking that may be more critical in terms of permeability, namely, cracking due to restraint of drying shrinkage. Restrained shrinkage cracks can form through the full depth of a member and thereby increase the permeability through the depth. This chapter reviews the factors affecting the magnitude of drying shrinkage and presents a simple model to calculate when shrinkage cracking would occur in a fully restrained member. Subsequently, methods for predicting crack widths due to restrained shrinkage are discussed.

\subsection{Factors Affecting Drying Shrinkage}

The report of ACI Committee 209 (ACI 209R-82) provides a comprehensive summary of the factors affecting drying shrinkage and is the source of the following review. The term drying shrinkage refers to the reduction in volume of hardened concrete as a result of evaporation of free water, that is, the water not chemically combined with cement during hydration. The shrinkage potential of a given concrete is primarily affected by the following factors:

- water-cement ratio,

- elastic stiffness of coarse aggregate, and

- relative volume fractions of cement paste and aggregate.

The approximate range of the ultimate unrestrained drying shrinkage strain under standard conditions $^{8}$ is between 400 and $1100 \times 10^{-6}$, depending on mixture proportions and aggregate characteristics. For a specific concrete mixture, the actual drying shrinkage strain depends on:

- elapsed time after the end of the initial curing period during which the concrete is protected from drying,

- duration of the initial curing period,

- ambient relative humidity, and

- volume-to-surface ( $\mathrm{v} / \mathrm{s})$ ratio of the member

The report of $\mathrm{ACI}$ Committee 209 provides approximate procedures to account for these factors (ACl 209R-82).

${ }^{8} \mathrm{According}$ to ACI 209R-82, standard conditions are defined as follows: initial curing period of 7 days, an ambient relative humidity of $40 \%$, and a volume-to-surface ratio of $38 \mathrm{~mm}$. 


\subsubsection{Elapsed time}

The amount of unrestrained shrinkage, $\epsilon_{s h}(t)$, as a function of elapsed time after the end of wet curing is given approximately by the following hyperbolic equation:

$$
\epsilon_{s h}(t)=\frac{t}{35+t} \epsilon_{s h, u}
$$

where $t=$ elapsed time after end of wet curing (days), and

$\epsilon_{s h, u}=$ ultimate shrinkage strain.

In this hyperbolic equation, the constant 35 represents the number of days to attain $50 \%$ of the ultimate shrinkage strain. The value of the ultimate shrinkage strain, $\epsilon_{\mathrm{sh}, u}$, is obtained by multiplying the ultimate unrestrained shrinkage strain under standard conditions by appropriate modification factors (see below). In the absence of data for the specific concrete, the recommended ultimate shrinkage strain under standard conditions is $780 \times 10^{-6}$. Thus the ultimate shrinkage strain under non-standard conditions can be assumed to be as follows:

$$
\epsilon_{s h, u}=780 \times 10^{-6} \prod_{i}^{n} \gamma_{s h, i}
$$

where $\gamma_{s h, i}=$ shrinkage strain correction factor due to the $i t h$ influence, and

II $=$ the product of correction factors.

According to ACI 209R-82, the product of the above correction factors cannot be less than 0.2 and the value of $\epsilon_{s h, u}$ has to be at least $100 \times 10^{-6}$ if concrete is exposed to seasonal wetting and drying and at least $150 \times 10^{-6}$ if it is exposed to sustained drying. The principal correction factors given by ACI Committee 209 are for the following: (1) duration of the initial curing period, (2) the ambient relative humidity, and (3) the specimen size (or volume-to-surface area ratio).

\subsubsection{Duration of the curing period}

The standard condition assumes that the concrete is moist-cured for seven days before it is exposed to drying conditions. The value of ultimate shrinkage decreases as the duration of the curing period increases. The correction factor for duration of curing is shown in Fig. 4.1(a), which indicates that, if the moist curing period is extended from 7 to 28 days, the ultimate shrinkage can be reduced to about $85 \%$ of the value for 7 days of moist curing.

\subsubsection{Ambient relative humidity}

The standard condition assumes that the ambient relative humidity during drying is $40 \%$. If the ambient relative humidity is greater then $40 \%$, the ultimate shrinkage is reduced. The correction factor for relative humidity is shown in Fig. 4.1(b). It is seen that there is a linear decrease in the correction factor from 1.0 to 0.6 as the relative humidity increases from 40 to $80 \%$, and the factor 
decreases to zero as the relative humidity increases from $80 \%$ to $100 \%$. Thus control of the ambient relative humidity is an effective means to control the magnitude of drying shrinkage.

\subsubsection{Volume-to-surface ratio}

Since shrinkage is due to migration of water out of the concrete, it has been found that the ultimate shrinkage decreases as the ratio of volume to surface area $(v / s)$ of the concrete member increases. The ultimate shrinkage under standard condition assumes that the value of $v / s$ is $38 \mathrm{~mm}$. The geometric correction factor given in ACI 209R-82 is as follows:

$$
\gamma_{s h, v / s}=1.2 e^{-0.00472 v / s}
$$

where $v / s=$ the volume-to-surface ratio $(\mathrm{mm})$.

This equation is plotted in Fig. 4.1(c).

\subsection{Creep Coefficient}

Prediction of the long-term behavior of a loaded reinforced concrete member is complicated by the phenomena of creep and stress relaxation. Creep refers to the increase in strain under sustained stress, and stress relaxation refers to the decrease in the stress required to maintain the concrete at a constant strain. As a result of these phenomena, concrete is capable of withstanding higher strains under sustained loading prior to cracking than under short-term loading. This makes it difficult to use the properties measured from standard short-term tests to predict whether cracking will occur under conditions of restrained drying shrinkage.

Figure 4.2 is a schematic curve of strain versus time to explain the terminology associated with creep. It is assumed that a constant axial stress is applied at an age $t_{0}$ which results in an initial strain $\epsilon_{0}$. Due to creep, the strain increases with elapsed time as shown in the figure. At any time $t$, the ratio of the creep strain to the initial elastic is called the creep coefficient, $\phi(t)$. The total strain at time $t$ is $\epsilon_{0}(1+\phi(t))$. An equation, recommended in ACl 209R-82, for the relationship between the creep coefficient and time is as follows:

$$
\phi(t)=\frac{\left(t-t_{0}\right)^{0.6}}{10+\left(t-t_{0}\right)^{0.6}} \phi_{u}
$$

where $\phi(\mathrm{t})=$ creep coefficient at time $t$,

$t=$ time (days),

$t_{0}=$ age when stress is applied (days), and

$\phi_{u}=$ ultimate value of creep coefficient. 


\subsubsection{Correction factors}

The ultimate value of the creep coefficient, $\phi_{t r}$ is determined in a similar manner as the ultimate shrinkage strain, that is, the ultimate creep coefficient under standard conditions ${ }^{9}$ is multiplied by a series of correction factors. According to ACI 209R-82, in the absence of specific data, the ultimate value of the creep coefficient under standard conditions can be assumed to be 2.35 . Figure 4.3 shows correction factors given in ACI $209 \mathrm{R}-82$ to obtain the ultimate value of the creep coefficient for loading ages other than 7 days, for relative humidity different from $40 \%$, and for $v / s$ different from $38 \mathrm{~mm}$. The correction factor, $\gamma_{\mathrm{a}}$, for the age, $t_{0}$ (in days), when the load is applied is shown in Fig. 4.3(a) and is based on the following equation:

$$
\gamma_{a}=1.25 t_{0}^{0.118}
$$

The correction factor for relative humidity, $\gamma_{\mathrm{h}}$, decreases linearly to a limiting value of 0.6 at $100 \%$ relative humidity, as shown in Fig. 4.3(b). The correction factor for volume-to-surface ratio, $\gamma_{\mathrm{v} / \mathrm{s}}$, is given by the following equation:

$$
\gamma_{v / s}=\frac{2}{3}\left(1+1.13 e^{-0.54 \frac{v}{s}}\right)
$$

where $v / s$ is in $\mathrm{mm}$. The variation of this geometric correction factor is shown in Fig. 4.3(c).

\subsection{Age-adjusted Effective Modulus}

Because of the effects of creep (or stress relaxation) and shrinkage, long-term stresses and strains in concrete are not related to each other by the linear-elastic Hooke's law. Various technical committees have attempted to develop practical methods for predicting the long-term response of concrete structures.

Two different situations are possible when attempting to predict long-term response due to sustained stresses or strains (ACI 209R-82). In one case, the gradual change in stress with time due to creep and shrinkage is small and has little effect on the response. For this condition, the response can be predicted by using the effective modulus approach, in which stress and strain are related by an effective modulus of elasticity, $E_{c e}$, that is given by the following:

$$
E_{c e}(t)=\frac{E_{c i}}{1+\phi(t)}
$$

where $E_{c i}=$ the short-term elastic modulus of the concrete at the time of load application, and

$\phi(t)=$ the creep coefficient.

${ }^{9}$ Standard conditions are the same as previously described for drying shrinkage, except that load is applied after moist curing for 7 days. 
According to ACI 209R-82, the effective modulus approach is applicable to predict creep deformations in statically determinate structures ${ }^{10}$. To implement the effective modulus approach, an elastic analysis is performed and the deformations are calculated as a function of time by using $E_{c e}$ instead of the short-term elastic modulus, $E_{c i}$.

The other case involves those structures in which the time rate of change in stress due to creep and drying shrinkage is significant. An example would be a statically indeterminate structure ${ }^{11}$ that is subjected to an imposed deformation. Because of creep and stress relaxation, the induced stresses would undergo redistribution with time. When stresses change with time, the deformation response cannot be predicted by using only the creep coefficient. This is because the creep coefficient is based on the assumption that the sustained load is applied at a particular instant in time and that it remains constant thereafter. In addition, the short-term elastic modulus changes with time and this affects how the stresses are redistributed. It has been found (ACI 209R-82) that, for this second class of problems, the response can be predicted adequately by using an age-adjusted effective modulus, $E_{c a}(t)$, that is defined as follows:

$$
E_{c a}(t)=\frac{E_{c i}}{1+\chi(t) \phi(t)}
$$

where $\chi(t)$ is called the aging coefficient. The aging coefficient is determined from calculations of the stress relaxation function (variation of stress with time under an imposed unit strain) (Bazant 1972). The aging coefficient depends on the following factors:

- age when the load (or deformation) is applied,

- the value of the ultimate creep coefficient, and

- the elapsed time from when the loading was applied.

Figure 4.4 shows how these factors affect the aging coefficient; the figure is based on tabulated values of the aging coefficient (Bazant 1972). It can be seen that the ultimate creep coefficient and the age at time of loading have the greatest effects on the aging coefficient, while the elapsed time beyond the application of the load has a minor effect.

To predict the long-term response of a statically indeterminate structure, a routine elastic analysis is performed and the age-adjusted effective modulus is used in place of $E_{c i}$. By evaluating the ageadjusted modulus at different ages, the designer can predict the history of the response. The next section illustrates the application of this approach to predict the tensile stresses that develop in a member restrained at its ends and undergoing drying shrinkage.

${ }^{10}$ Structures in which the forces present in the members are obtained by considering only the equilibrium of forces, and these forces are not related to member stiffnesses.

${ }^{11} \mathrm{~A}$ complex structure with redundant members so that the member forces cannot be determined by applying only the equations of equilibrium. The forces depend on the stiffnesses of the members. 


\subsection{Prediction of Cracking due to Restrained Shrinkage}

The age-adjusted effective modulus approach and the creep and shrinkage relationships given in ACI 209R-82 are used in a simplified example to predict whether cracking will occur in a plain concrete member when there is full restraint to drying shrinkage. The member is a $0.76-\mathrm{m}$ thick slab with length and width of $7.3 \mathrm{~m}$. These dimensions are assumed to be representative of the roof slab of a buried vault for low-level nuclear waste (Shuman, et al. 1988). It is assumed that the slab is completely restrained along two opposite edges. The objective is to predict the induced tensile stress as the slab is exposed to drying conditions. The induced stress is compared with the concrete tensile strength to determine whether the slab will crack.

If the slab were made of a liner-elastic material, the induced tensile stress would be given by the following simple relationship:

$$
\sigma(t)=E_{e l} \epsilon_{s h}(t)
$$

where $E_{e l}$ is the modulus of elasticity and $\epsilon_{s h}(t)$ is the shrinkage strain that would occur if there were no restraint. Thus the tensile stress would be proportional to the amount drying shrinkage. However, because of creep and stress relaxation, the induced tensile stress in concrete would be less than predicted by Eq. (4.9). The age-adjusted effective modulus approach permits an improved estimate of the tensile stress as function of time by using $E_{c a}(t)$ in place of $E_{e l}$ in Eq. (4.9).

Analyses were performed for two durations of the curing period, 7 and 28 days, and for three values of ambient relative humidity, namely, 40,60 and $80 \%$. Thus a total of six conditions were examined. The following steps were used:

- For each of the six conditions, calculate the ultimate values of the unrestrained shrinkage strain, $\epsilon_{s h w}$ and of the creep coefficient, $\phi_{u}$, by applying the correction factors (Fig. 4.1 and 4.3) given in $\mathrm{ACI} 209 \mathrm{R}-82$ to the nominal values under standard conditions. Figure 4.5(a) shows the ultimate values of unrestrained shrinkage strain and creep coefficient for the six conditions.

- Using tabulated values of the aging coefficient (Bazant 1972), estimate the aging coefficients for loading ages (when drying begins) of 7 and 28 days. The aging coefficient was assumed to be linear function of $\log t_{0}$ for $t_{0}$ equal to 10 and 100 days. The estimates were obtained from the tabulated values for $\phi_{u}$ equal to 0.5 and 1.5.

- Using the estimates of the aging coefficients for $t_{0}$ of 7 and 28 days, interpolate to find the aging coefficients for $\phi_{u}$ corresponding to each of the six conditions. The aging coefficient was assumed to be a linear function of $\phi_{\mathrm{u}}$, as $\phi_{\mathrm{u}}$ varied between 0.5 and 1.5 .

- These two steps gave estimates of the aging coefficients at elapsed times $\left(t-t_{0}\right)$ of 10,100 , 1000 , and 10000 days. The final step was to plot the aging coefficient versus $\log \left(t-t_{0}\right)$ and estimate the aging coefficient at intermediate values of elapsed time by interpolation.

- At each value of elapsed time, compute the unrestrained shrinkage strain and age adjusted effective modulus. The product of these two quantities is the induced stress due to restrained drying shrinkage. 
- Compare the induced stress with the tensile strength. The time at which the induced stress exceeds the tensile strength is when the slab will crack.

For these analyses, Eqs. (4.1) and (4.4) were used to represent the time functions for the development of shrinkage and creep. In addition, the following relationships were assumed for tensile strength, short-term elastic modulus, and compressive strength gain ( $\mathrm{ACl} 209 \mathrm{R}-82$ ):

$$
\begin{aligned}
f_{t} & =0.33 \sqrt{f_{c}} \\
E_{c i} & =4740 \sqrt{f_{c}} \\
f_{c} & =f_{c, u} \frac{t}{7+t}
\end{aligned}
$$

where $f_{t}=$ tensile strength $(\mathrm{MPa})$,

$f_{c}=$ compressive strength $(\mathrm{MPa})$,

$E_{c i}=$ short-term modulus of elasticity (MPa),

$f_{c, u}=$ ultimate compressive strength (MPa), and

$t=$ age (days).

The formula for compressive strength gain assumes that the 28 -day strength is $80 \%$ of the ultimate strength. Temperature is assumed to be constant and equal to the standard temperature of $23^{\circ} \mathrm{C}$..

Figure 4.5(b) shows the time functions for the development of strength (tensile and compressive), shrinkage strain and creep coefficient. Note that age for creep and shrinkage refers to the elapsed time from the end of the curing period, whereas for tensile and compressive strength it represents the age beyond the time of setting. The 28-day compressive strength of the concrete was assumed to be $27.6 \mathrm{MPa}$. However, because tensile strength and elastic modulus are assumed to be proportional to the square root of compressive strength, it can be shown that the time at which cracking occurs is independent of the 28-day concrete strength.

The results of the analyses are summarized in Fig. 4.6. Figure 4.6(a) shows the results for an initial curing period of 7 days. As the ambient humidity increases, the induced tensile stresses are reduced, and the model predicts that cracking would not occur for an ambient relative humidity of $80 \%$ and above. Prolonging the curing period from 7 to 28 days has the following effects:

- reduces the ultimate shrinkage strain,

- increases the aging coefficient,

- increases the elastic modulus at age of loading, and

- reduces the ultimate creep coefficient.

The first and second of these effects tend to reduce the induced tensile stress as a function of time, whereas the third and fourth effects tend to increase the stress. Figure 4.6(b) shows that, compared with 7 days of curing, a curing period of 28-days results in cracking at an earlier time, and cracking occurs even with $80 \%$ relative humidity. In this case, the increased induced stress arising from a 
higher elastic modulus and a reduced creep coefficient dominate over the other effects. Thus the notion that prolonged curing is always desirable may not be correct when dealing with restrained drying shrinkage. While it desirable to reduce shrinkage strain, it is also desirable to increase creep. There is, therefore, an optimum duration for the curing period that results in the lowest induced tensile stress.

To summarize, based on this simple analysis using the age-adjusted effective modulus, cracking of the slab is predicted to occur at the ages shown in Table 4.1. Note that for the 28-day curing period, cracking is predicted to occur at an earlier age for exposure at $80 \%$ relative humidity than for exposure at $60 \%$ relative humidity. This apparent anomalous behavior is because exposure at $80 \%$ reduces the creep coefficient, which results in a higher induced tensile stress.

The above example has been presented to illustrate the interaction of the various factors involved in predicting restrained shrinkage cracking. In a real structure, it is unlikely that there would be complete restraint against drying shrinkage. In addition, the designer can reduce the induced stresses by proper design details which reduce the restraint to drying shrinkage. Therefore, the results of these simple analyses should not be interpreted to mean that shrinkage cracking is inevitable.

\subsection{Prediction of Crack Width and Spacing}

The previous section has discussed whether drying will lead to cracking when there is complete restraint to the resulting shrinkage. This section examines the prediction of crack width and spacing due to restrained drying shrinkage. The discussion is based on the work of Base and Murray (1982), Tam and Scanlon (1986a), and Gilbert (1992). The mechanisms of shrinkage cracking involve some of the same considerations that were discussed in Chapter 3 for flexural cracking.

First, consider the changes in stresses that occur in a restrained member undergoing drying shrinkage. Figure 4.7(a) shows a reinforced concrete member restrained at its ends. As the concrete begins to dry out, the tensile stress in the concrete increases with time, as shown in the stress history plot to the right of the member. The steel bar, however, remains unstressed because its length is unchanged. The method for calculating the tensile stress in the concrete was discussed in the previous section. Under unfavorable conditions, the tensile stress will surpass the tensile strength of the concrete and a crack will develop. If there is no reinforcement, a single crack forms and its width increases with time in direct proportion to the amount of drying shrinkage (crack width equals shrinkage strain times the length of the member). If there is reinforcement, a crack will still develop when the tensile stress exceeds the tensile strength of the concrete, but the crack width is much narrower compared with the unreinforced case.

The formation of the first drying shrinkage crack leads to changes in the stress distribution within the member, as shown in Fig. 4.7(b). First, the concrete stress at the location of the crack is reduced to zero. Due to this stress relief, the concrete tends to contract. However, bond with the reinforcement restrains the contraction, and a tensile stress builds up in the concrete over the slip length, $S_{0}$. Beyond the slip length, the concrete tensile stress remains constant at a value of $f_{c l}$. This 
slip length is analogous to one-half the slip length, $l_{s, \max }$, discussed in 3.2 in regard to flexural cracking. The following relationship is used to estimate $S_{0}$ :

$$
S_{0}=\alpha \frac{\phi}{\rho}
$$

where $\alpha$ is a constant (equal to 0.08 according to Base and Murray (1982) and equal to 0.1 according to Gilbert (1992)), $\phi$ is the bar diameter, and $\rho$ is the reinforcement ratio (area of steel divided by area of concrete).

The concrete stress, $f_{c l}$, after the formation of the first crack is less than the tensile strength of the concrete, as shown in the stress history to the right of the member in Fig. 4.7(b). Cracking makes the member more flexible which leads to an overall reduction in the induced tensile stress in the uncracked portion of the concrete. The crack causes a high tensile stress, $f_{s 2}$, to develop in the steel at the location of the crack. The product of the steel area, $A_{s}$, and $f_{s 2}$ equals the total tensile force in the member after cracking. The steel stress decreases over the slip length until it reaches a constant compressive stress of $f_{s l}$. The compression stress in the steel is necessary to assure that the overall length of the bar remains unchanged. By considering the basic requirements of equilibrium of forces and compatibility of deformations, Gilbert (1992) developed a series of equations to determine the resulting stresses after first cracking. In the derivation, it was assumed that the steel stress variation within the slip zone was parabolic.

After the formation of the first crack, the tensile stress in the concrete will increase with time as further drying shrinkage occurs. If the tensile stress reaches the tensile strength of the concrete, a new crack develops and stress relief occurs again in the concrete. This process is repeated until there is no longer any tendency for shrinkage, and the final, or stabilized, crack pattern is established as shown in Fig. 4.7(c). The changes in concrete stress with time are shown to the right of the sketch of the cracked member, and the stabilized stress distributions in the concrete and steel are shown below the member.

The above has provided a qualitative explanation of the mechanism of restrained shrinkage cracking. Technique to predict crack width and spacing are discussed next. Base and Murray (1982) presented a series of equations to estimate the number of cracks, the stress in the steel at the location of the cracks, and the average crack width when there is complete restraint to shrinkage (drying shrinkage and thermal shrinkage). These estimates depend on the following parameters:

- the length of the member,

- the effective modulus of elasticity of concrete (accounting for creep),

- the magnitude of the shrinkage strain,

- reinforcement ratio,

- bar diameter, and

- the tensile strain limit of the concrete (as measured in short-term tests).

The equations by Base and Murray were used in this study to prepare Fig. 4.8, which shows, for a 10-m long member, (a) the number of cracks, (b) the steel stress at the cracks, and (c) the average 
crack width as a function of the shrinkage strain and amount of reinforcement. The calculations are based on the following assumptions:

- the concrete tensile strain limit is 100 microstrain,

- the modular ratio (modulus of elasticity of the steel divided by the effective modulus of elasticity of the concrete) is 16 , and

- the ratio of bar diameter to reinforcement ratio $(\phi / \rho)$ is 2500 .

A study of the plots in Fig. 4.8 shows the following:

- The number of cracks increases as the shrinkage strain and amount of reinforcement increases.

- The steel stress decreases as the amount of reinforcement increases. Generally, the steel stress decreases with increasing shrinkage strain.

- The crack width decreases as the amount of reinforcement decreases. For a low reinforcement ratio, crack width increases with shrinkage strain. However, as the reinforcement ratio increases, crack width is affected little by the value of the shrinkage strain.

These results illustrate the key principles in using reinforcement for shrinkage crack control. The addition of steel does not prevent cracking due to restrained shrinkage, but it limits crack width by causing the formation of many narrow cracks rather a single wide crack, as would be the case if reinforcement were absent. Furthermore, the magnitude of the sbrinkage strain plays a secondary role with respect to crack widths, but it influences strongly the number of cracks that may develop.

The prediction equations proposed by Base and Murray (1982) are based on numerical analyses of restrained members using the finite difference method. Gilbert (1992), on the other hand, used the basic principles of equilibrium and compatibility to derive a series of expressions to calculate the final stresses in the concrete and steel, the number of cracks, and the average crack width. For this study, the equations developed by Gilbert (1992) were incorporated into a computer spreadsheet to permit the creation of plots similar to those in Fig. 4.8. In these calculations, it was assumed that concrete strength did not change with time; this assumption is reasonable because the analysis considers behavior after the formation of the first crack, which occurs usually at a late age (see Fig. 4.6). The effects of creep are taken into account by using the effective modulus of elasticity of the concrete according to Eq. (4.7). To compare with the results of Base and Murray, similar values of creep coefficient and bar diameter divided by reinforcement ratio were used. The tensile strength of the concrete was assumed to be $2.5 \mathrm{MPa}$, and the short-term modulus of elasticity was assumed to be $25,000 \mathrm{MPa}$, which correspond to a short-term tensile strain limit of 100 microstrain. The results of the calculations based on Gilbert's approach are shown in Fig. 4.9.

Comparison of Figs. 4.8 with Fig. 4.9 shows strikingly similar trends. The noticeable exception occurs at a shrinkage strain of 0.0002 , where crack widths predicted by Gilbert's method deviate from the trend at higher shrinkage values. This discrepancy is believed to be caused by the fact that Gilbert's equations are based on the presence of multiple cracks. However, at the low shrinkage strain of 0.0002 , only one crack is predicted, and the equations are probably inappropriate. Discounting this discrepancy at the low shrinkage strain, it can be seen that the two methods result in similar predictions of crack width as a function of reinforcement ratio and shrinkage strain. 
The major differences between the two prediction methods are the number of cracks and the steel stress at the cracks. Gilbert's method predicts approximately three times the number of cracks compared with Base and Murray's method. The predicted steel stress is approximately two times greater by Gilbert's method. An earlier equation for crack width by Base and Murray (1982) resulted in similar numbers of cracks as Gilbert's method. However, that equation was modified to account for the influence of creep, and the modification resulted in a lower number of predicted cracks shown in Fig. 4.8. Without benefit of extensive data, it is not possible to judge which of these two methods results in the most realistic crack pattern. However, the important point is that both methods result in the same predictions in regard to the effects of the major variables on restrained shrinkage cracking.

Tam and Scanlon (1986a) also performed analyses of crack development due to restrained drying shrinkage. By calculating the variation of concrete stress as a function of time (as shown schematically in Fig. 4.7(b)), they determined when cracks would occur in a 190-mm thick slab restrained along two edges. Crack widths, however, were not estimated. The age functions given in ACI 209R-82 were used for the development of drying shrinkage strain and the creep coefficient, and the ultimate values for these two quantities were assumed to be 800 microstrain and 2.35, respectively. The age-adjusted effective modulus was used to relate concrete stress and strain. For simplicity, the aging coefficient was assumed to be constant and equal to 0.8. Tam and Scanlon (1986a) carried out a parametric study to investigate the effects of the following factors: span length, steel area, bar size, and the relationship used to calculate the slip length. The number of predicted cracks are summarized in Table 4.2. It can be seen that the relationship used for the slip length had a strong effect on the predicted number of cracks. Based on their analyses, Tam and Scanlon reported the following conclusions (1986a):

- The number of cracks increases with span length, therefore crack spacing is essentially independent of span length.

- The number of cracks increases with the amount of reinforcement.

- Larger bar sizes lead to fewer cracks, but the cracks would be wider.

In summary, Tam and Scanlon's (1986a) analyses confirmed the general principles of shrinkage crack control that have been discussed. Note that the number of cracks for the case where slip length is based on $\phi / \rho$ are lower than the numbers shown in Figs. 4.8 and 4.9 for a shrinkage strain of 0.0008 . This difference is likely a result of the larger creep coefficient used by Tam and Scanlon, which results in lower induced stresses due to shrinkage.

To conclude this study, Gilbert's method was used to predict the cracking that would occur under conditions of complete restraint along opposite edges of the 760 - $\mathrm{mm}$ thick slab mentioned in the previous section. The values of ultimate drying shrinkage and creep coefficient given in Fig. 4.5 were used to predict the numbers and widths of cracks for different amounts of reinforcement. The computed average crack width and number of cracks are given in Table 4.3, and Fig. 4.10 shows how these quantities were affected by the amount of reinforcement and exposure conditions. As expected, by increasing the amount of reinforcement, the crack width is reduced and the number of cracks increases. It is noted that for a reinforcement ratio above 0.012 , crack width is not affected 
much by the exposure condition, whereas the number of cracks is generally greater for the more severe conditions.

\subsection{Interaction of Flexural and Drying Shrinkage Cracking}

Chapter 3 and this chapter have discussed separately the effects of flexural cracking and restrained shrinkage cracking so that the mechanisms could be understood. However, in actual structural elements, such as beams and slabs, flexural and shrinkage cracks can occur simultaneously. The interaction between these two crack types needs to be considered to understand the actual cracking expected in a restrained flexural member. To reiterate, a major difference between these two types of cracks is that flexural cracks do not extend through the full depth of a member, whereas shrinkage cracks may extend through the full depth.

In a simply-supported flexural member, one part of the cross section must carry the compression force to provide the internal bending moment to resist the applied external moment (refer to Fig. 2.3). This generally means that part of the concrete has to be in compression at all times, thereby eliminating the possibility of a crack through the full depth. In a continuous flexural member (a beam that is continuous over one or more supports), there is the possibility of the formation of a full depth crack at the inflection points (locations of zero bending moment).

To gain an understanding of the possible interactions between flexural and restrained shrinkage cracks, three conditions can be considered:

- The member is subjected to a bending moment that is larger than the cracking moment before drying shrinkage begins to occur.

- The member is subjected to a bending moment that is less than the cracking moment and drying shrinkage occurs.

- The member undergoes drying shrinkage prior to the application of the bending moment.

In the first case, the effect of shrinkage will be to increase the width of flexural cracks that have already formed due to the service load and to increase the number of flexural cracks. The major consequence of shrinkage will be to increase the deflection of the member. In the second case, the induced tensile stress is added to the tensile stress resulting from the flexural loading. As a result, flexural cracks will develop at a lower applied transverse load compared with the first case. In essence, the second case can be analyzed as though the shrinkage-induced tensile stress causes a reduction in the effective modulus of rupture of the concrete. This approach was used by Tam and Scanlon (1986b) to investigate the effects of drying shrinkage on the deflections of slabs, and it was concluded that the overall effect of the shrinkage was to increase slab deflection.

In the third case, the overall result depends on the reinforcement layout and the value of the subsequent bending moment. If the member is reinforced with steel on one face only, as shown in Fig. 2.3, full-depth shrinkage cracks that may have formed will close on the compression side of the member under the action of the transverse load. If the member is reinforced on both faces (tension and compression reinforcement), a full-depth shrinkage crack may or may not close when the transverse load is applied. If the bending moment is small, it is possible for the reinforcing steel to 
supply the necessary internal resisting moment, without the need of compression in the concrete (Base and Murray, 1982). In this case the, the full-depth crack will not close.

The report by Shuman, et al. (1988) indicates that the roofs of below ground disposal vaults would be constructed as slabs on grade, by filling the vaults with material prior casting the roof. If the fill material does not settle, it would prevent the roof from deflecting under the action of transverse loads. This would eliminate the tendency of the transverse load to close a drying shrinkage crack that may have formed. However, if the fill were to settle, there would be an interaction between flexural and shrinkage cracks.

\subsection{Summary}

This chapter has reviewed the considerations involved in the analysis of a reinforced concrete structure to predict cracking due to restrained drying shrinkage. The factors affecting the drying shrinkage of a particular structure were mentioned, and various correction factors were presented that permit an estimate of the ultimate shrinkage that may occur under a specific set of conditions. Restrained drying shrinkage is accompanied by creep, or stress relaxation, of the concrete which reduces the magnitude of the shrinkage-induced tensile stresses compared with an elastic material. ${ }^{12}$ The use of the age-adjusted effective modulus of elasticity, instead of the short-term modulus, provides a relatively simple approach to predict the development of tensile stress in a restrained member as it shrinks.

If the shrinkage-induced tensile stress surpasses the tensile strength of the concrete, a drying shrinkage cracks forms. The effects of the first shrinkage crack on the internal stress distribution were reviewed, and some of the approaches that have been developed to predict the final crack pattern (width and number of cracks) were discussed. Based on sample calculations using these methods, it was shown that shrinkage crack widths are primarily a function of the reinforcement ratio, whereas the number of cracks is dependent on the ultimate shrinkage strain as well as the amount of reinforcement.

The chapter concluded with a brief discussion of the interaction of flexural and shrinkage cracks. These interactions must be considered when attempting to predict the consequences of cracking.

${ }^{12}$ In an elastic material, the deformation caused by the applied load is recovered when the load is removed. There is no creep or stress-relaxation. 
Table 4.1 - Time of cracking due to restrained drying shrinkage of 0.76-m thick slab

\begin{tabular}{|c|c|c|}
\hline $\begin{array}{c}\text { Curing period, } \\
\text { days }\end{array}$ & $\begin{array}{c}\text { Relative } \\
\text { Humidity, } \\
\%\end{array}$ & $\begin{array}{c}\text { Time of cracking (beyond } \\
\text { end of curing period), days }\end{array}$ \\
\hline \multirow{2}{*}{7} & 40 & 70 \\
\cline { 2 - 3 } & 60 & 200 \\
\cline { 2 - 3 } & 80 & no cracking \\
\hline \multirow{2}{*}{28} & 40 & 45 \\
\cline { 2 - 3 } & 60 & 95 \\
\cline { 2 - 3 } & 80 & 80 \\
\hline
\end{tabular}

Table 4.2 - Number of cracks in restrained slab (Tam and Scanlon 1986a)

\begin{tabular}{|c|c|c|c|c|c|c|}
\hline \multirow{2}{*}{$\begin{array}{c}\text { Span } \\
\text { length, } \\
\text { mm }\end{array}$} & $\begin{array}{c}\text { Reinforcement } \\
\text { ratio, } \rho\end{array}$ & \multirow{2}{*}{$\begin{array}{c}\text { Diameter } \\
\phi, \mathrm{mm}\end{array}$} & $\phi / \rho$ & \multicolumn{4}{|c|}{ Number of cracks } \\
\cline { 5 - 7 } & & & & $\mathrm{S}_{0}=154 \mathrm{~mm}$ & $\mathrm{~S}_{0}=216 \mathrm{~mm}$ & $\mathrm{~S}_{0}=0.16 \phi / \rho$ \\
\hline 2000 & 0.003 & 10 & 3333 & 1 & 1 & 1 \\
\hline 4000 & 0.003 & 10 & 3333 & 2 & 2 & 1 \\
\hline 6000 & 0.003 & 10 & 3333 & 3 & 2 & 1 \\
\hline 8000 & 0.003 & 10 & 3333 & 4 & 3 & 1 \\
\hline 6000 & 0.002 & 10 & 5000 & 2 & 2 & 1 \\
\hline 6000 & 0.004 & 10 & 2500 & 4 & 3 & 1 \\
\hline 6000 & 0.005 & 10 & 2000 & 5 & 4 & 2 \\
\hline 6000 & 0.005 & 15 & 3000 & 5 & 4 & 1 \\
\hline 6000 & 0.005 & 20 & 4000 & 5 & 4 & 1 \\
\hline 6000 & 0.005 & 25 & 5000 & 5 & 4 & 1 \\
\hline
\end{tabular}


Table 4.3 - Cracking due to restrained shrinkage in a 760-mm thick, 7.3-m long slab using Gilbert's (1992) approach; 20-mm bars, compressive strength $=27.6 \mathrm{MPa}$

\begin{tabular}{|l|l|c|c|c|c|c|c|}
\hline \multirow{2}{*}{ Conditions } & & \multicolumn{6}{|c|}{ Reinforcement Ratio } \\
\cline { 3 - 8 } & & 0.006 & 0.008 & 0.010 & 0.012 & 0.014 & 0.016 \\
\hline 7 day & Number & 4 & 4 & 5 & 6 & 7 & 8 \\
$40 \% \mathrm{RH}$ & Width, mm & 0.19 & 0.13 & 0.12 & 0.11 & 0.10 & 0.09 \\
\hline 7 day & Number & 2 & 2 & 3 & 3 & 3 & 4 \\
$60 \% \mathrm{RH}$ & Width, mm & 0.19 & 0.09 & 0.16 & 0.12 & .08 & 0.11 \\
\hline 28 day & Number & 3 & 3 & 4 & 4 & 5 & 5 \\
$40 \% \mathrm{RH}$ & Width, mm & 0.20 & 0.13 & 0.13 & 0.10 & 0.10 & 0.08 \\
\hline 28 day & Number & 2 & 2 & 2 & 2 & 2 & 2 \\
$60 \% \mathrm{RH}$ & Width, mm & 0.27 & 0.22 & 0.17 & 0.12 & 0.08 & 0.04 \\
\hline 28 day & Number & 2 & 2 & 2 & 3 & 3 & 3 \\
$80 \% \mathrm{RH}$ & Width, mm & 0.22 & 0.15 & 0.09 & 0.14 & 0.12 & 0.09 \\
\hline
\end{tabular}



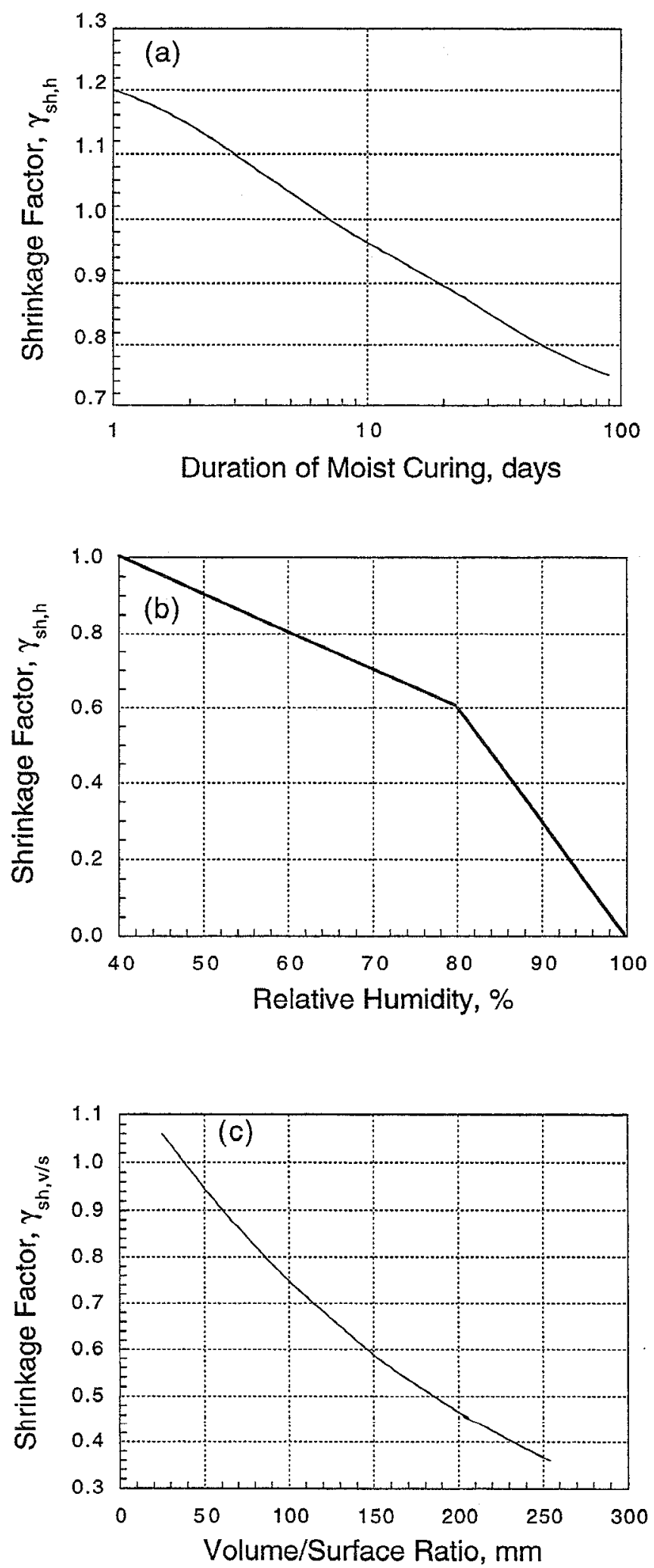

Figure 4.1 - Correction factors for unrestrained shrinkage strain given in ACI 209R-82: (a) duration of curing period; (b) ambient relative humidity; and (c) volume-to-surface ratio. 

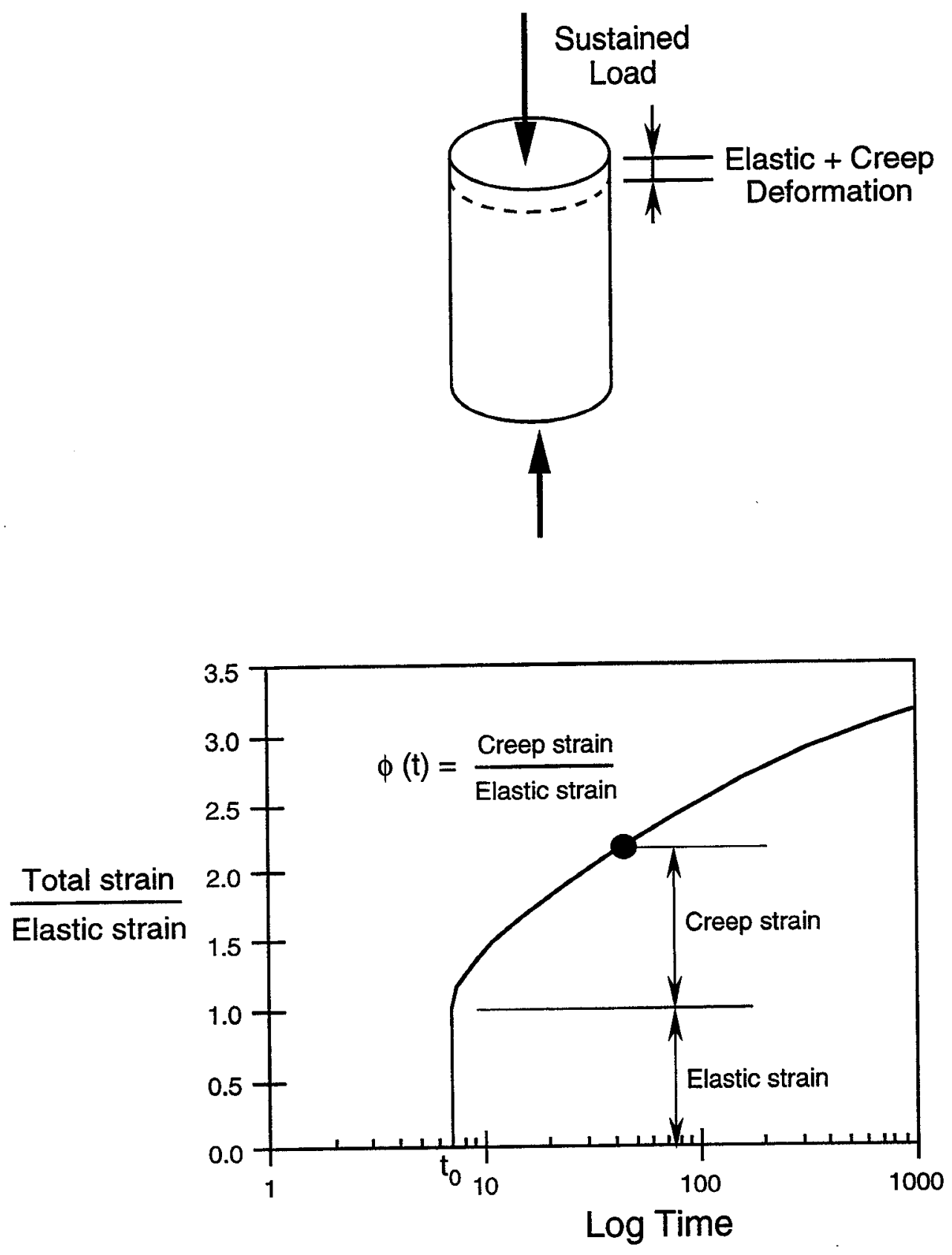

Figure 4.2 - Increase in strain with time due to creep under sustained stress. 

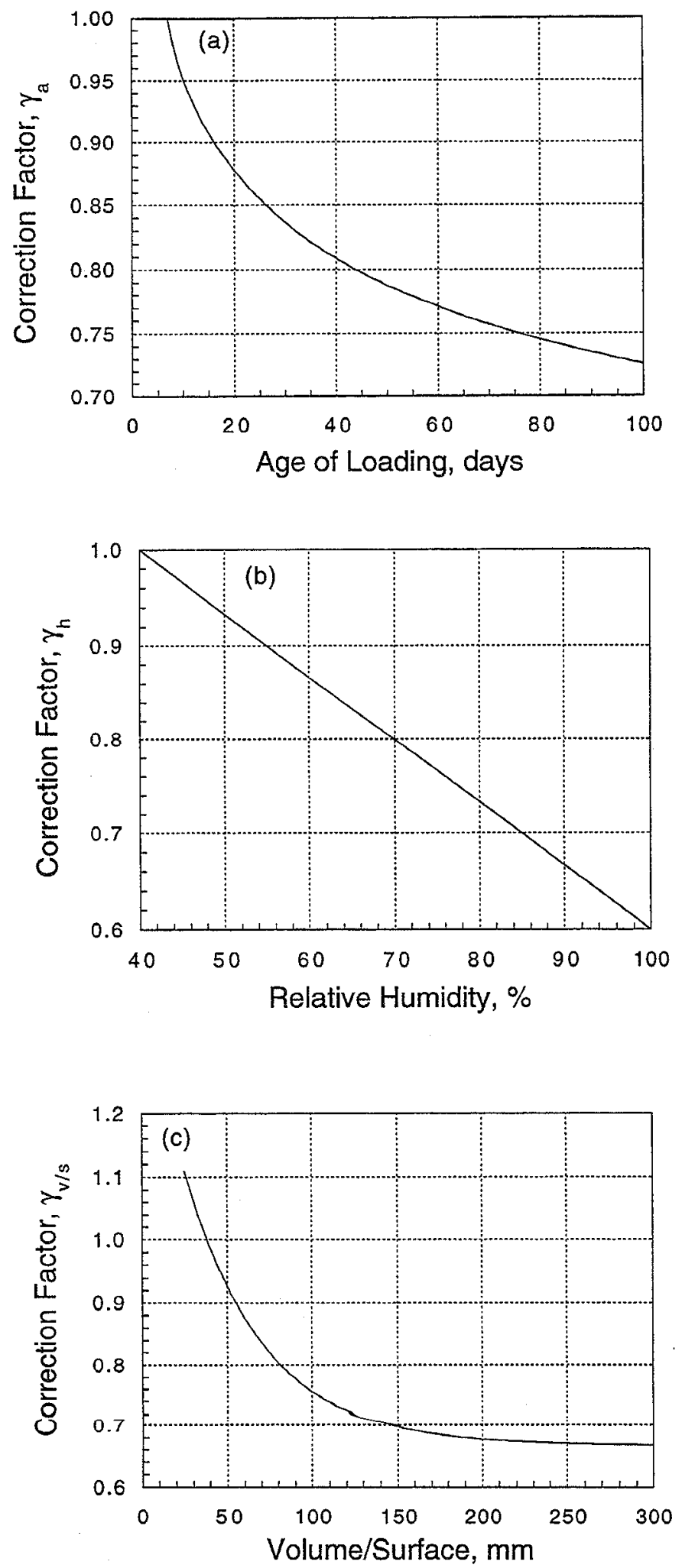

Figure 4.3 - Creep coefficient correction factors given in ACI 209R-82: (a) duration of curing period; (b) ambient relative humidity; and (c) volume-to-surface ratio. 

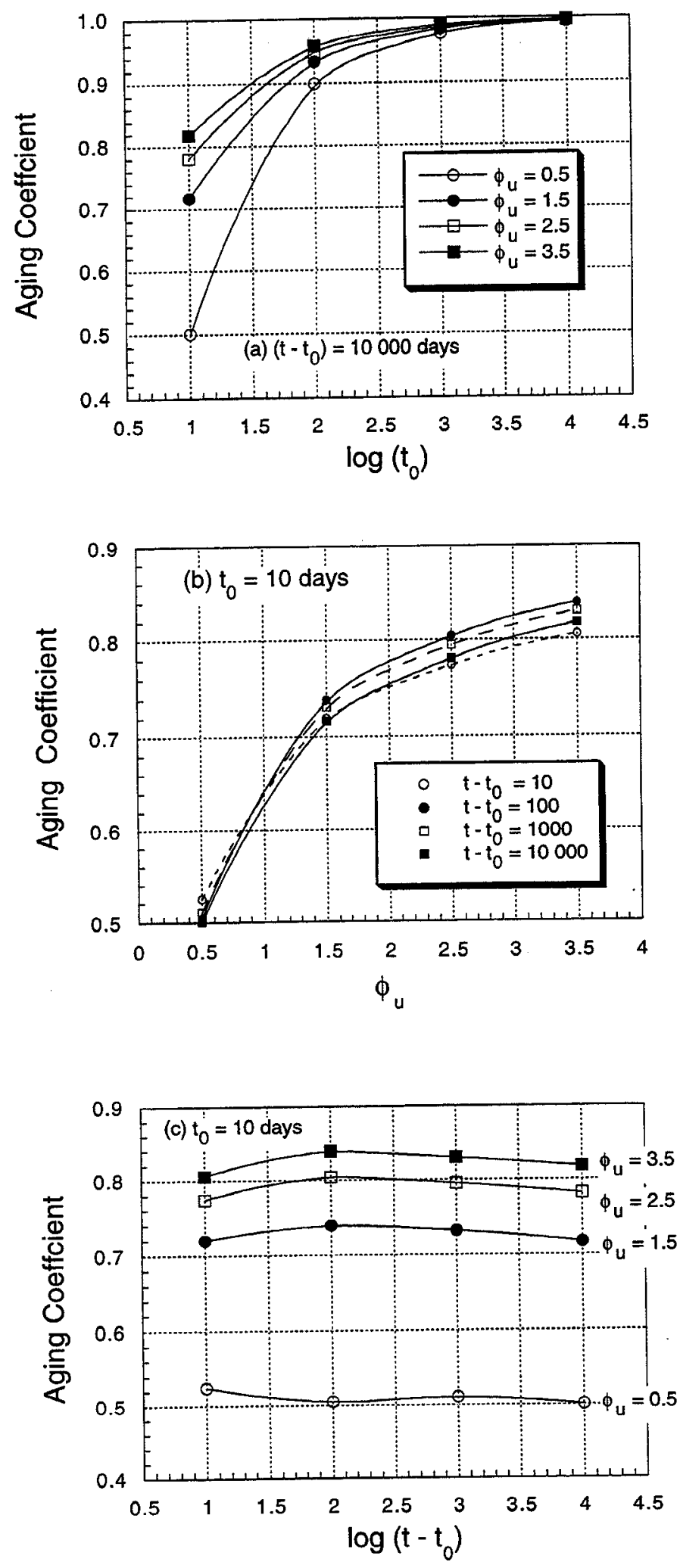

Figure 4.4 - Effects of various factors on the aging coefficient: (a) the age at load application; (b) the ultimate creep coefficient; and (c) the elapsed time from load application. 
(a)

Limiting Values

\begin{tabular}{|c|c|c|r|}
\hline $\mathrm{t}_{0}$, days & $\begin{array}{c}\text { Relative } \\
\text { Humidity, } \%\end{array}$ & $\varepsilon_{\text {sh,u }}$ & $\phi_{\mathrm{u}}$ \\
\hline \multirow{3}{*}{7} & 40 & 0.000234 & 1.57 \\
\cline { 2 - 4 } & 60 & 0.000187 & 1.37 \\
\cline { 2 - 4 } & 80 & 0.000156 & 1.15 \\
\hline \multirow{3}{*}{28} & 40 & 0.000201 & 1.32 \\
\cline { 2 - 4 } & 60 & 0.000161 & 1.15 \\
\cline { 2 - 4 } & 80 & 0.000156 & 0.97 \\
\hline
\end{tabular}

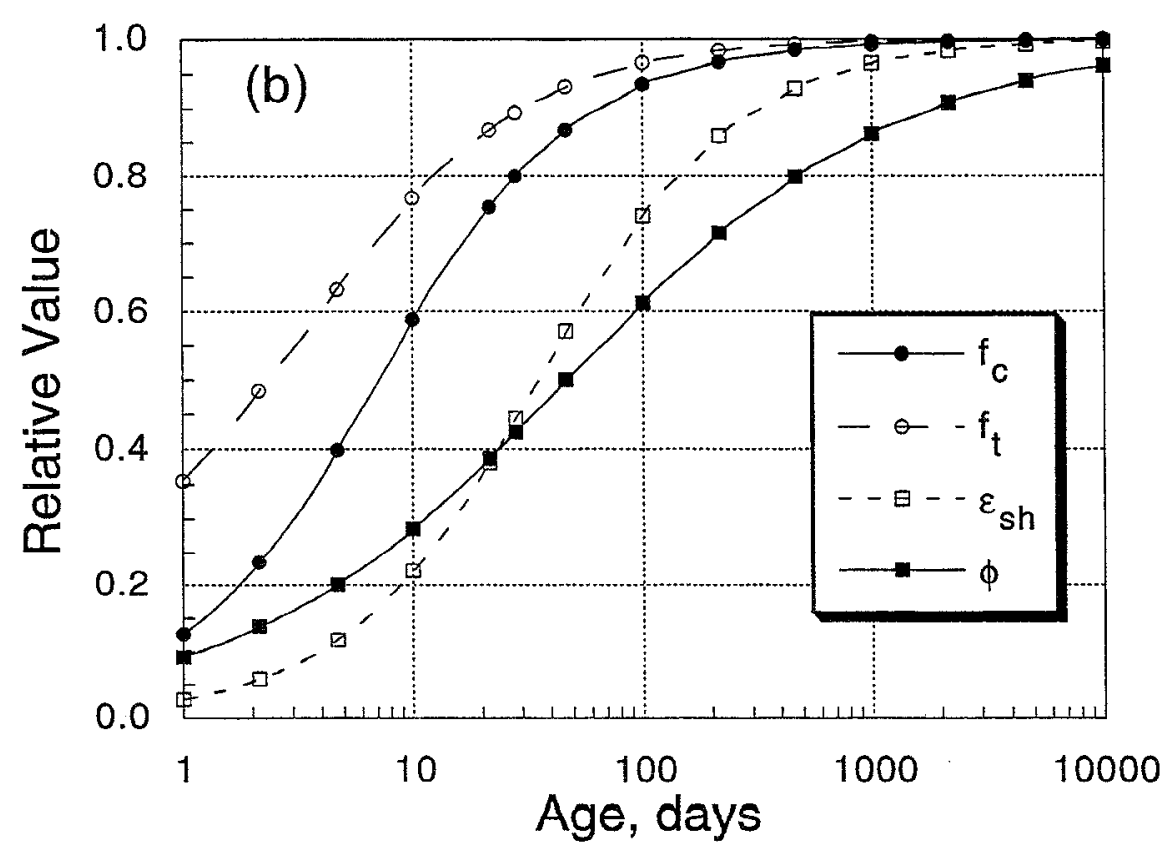

Figure 4.5 - (a) Ultimate values of unrestrained drying shrinkage and creep coefficient for the six conditions used in example problem; (b) time functions for development of strength, shrinkage and creep. 

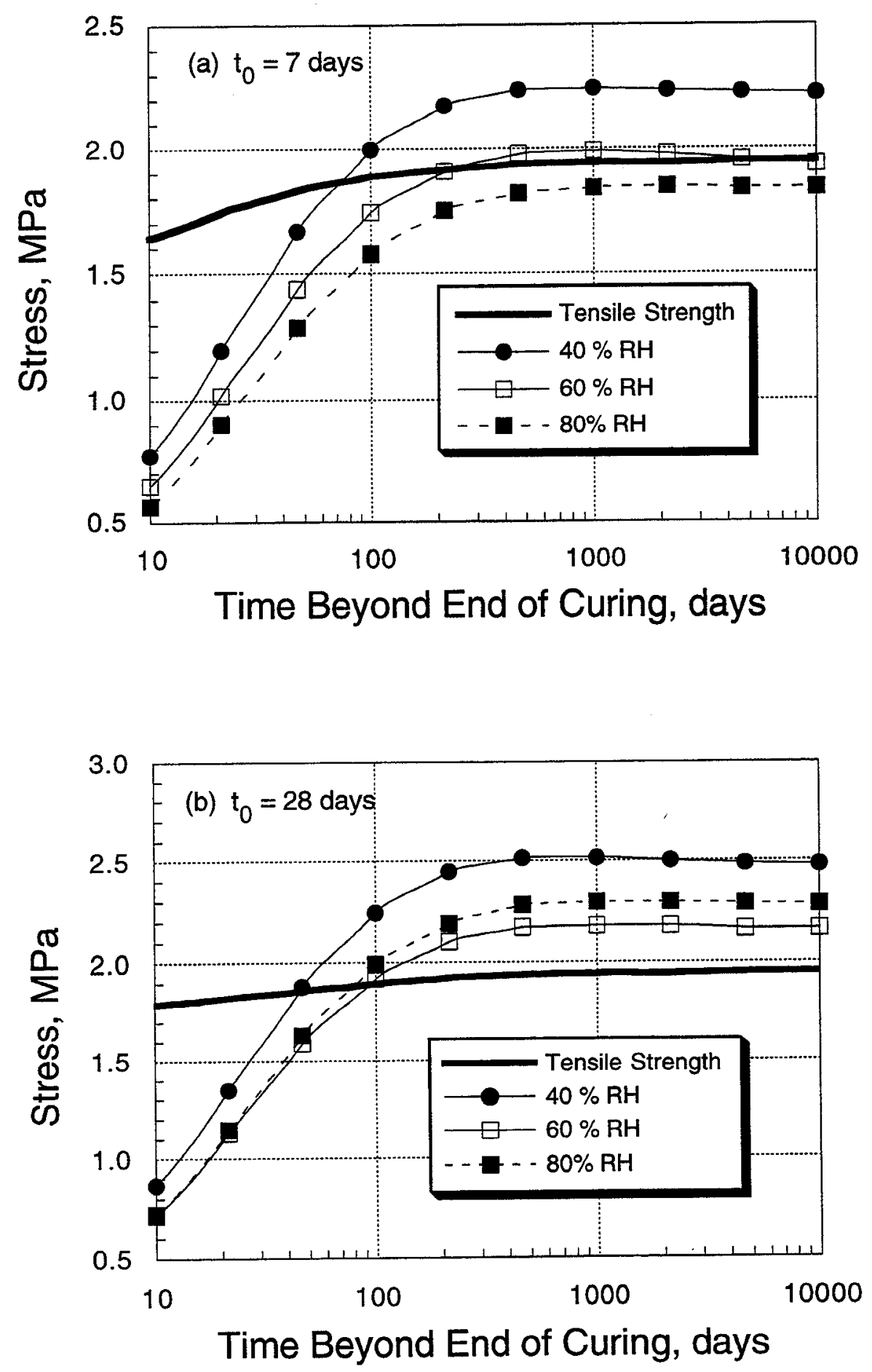

Figure 4.6 - Tensile stresses due to restrained drying shrinkage in a $0.76-\mathrm{m}$ thick slab for different values of ambient relative humidity: (a) for 7-day curing period and (b) for 28-day curing period. 
(a) Prior to first crack
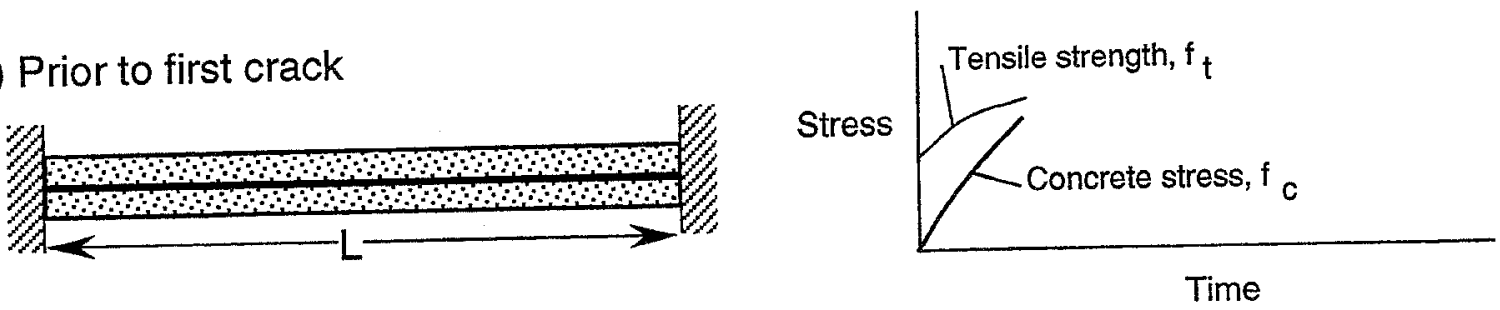

(b) Immediately after first crack
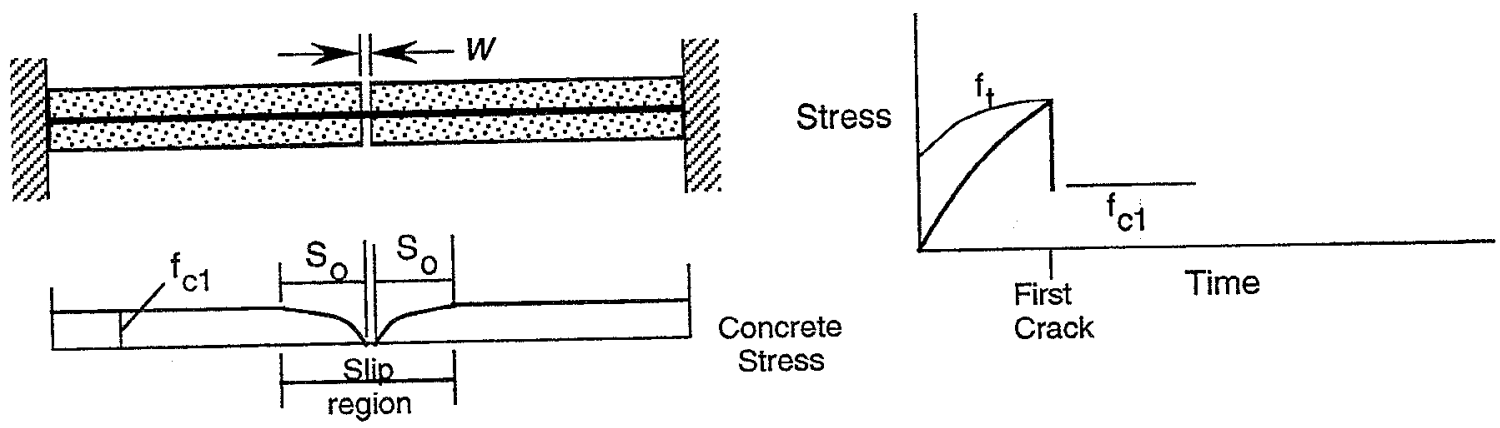

Crack

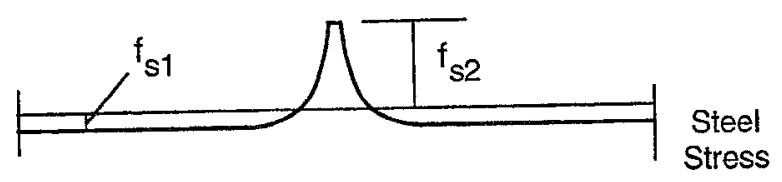

(c) Stabilized crack pattern
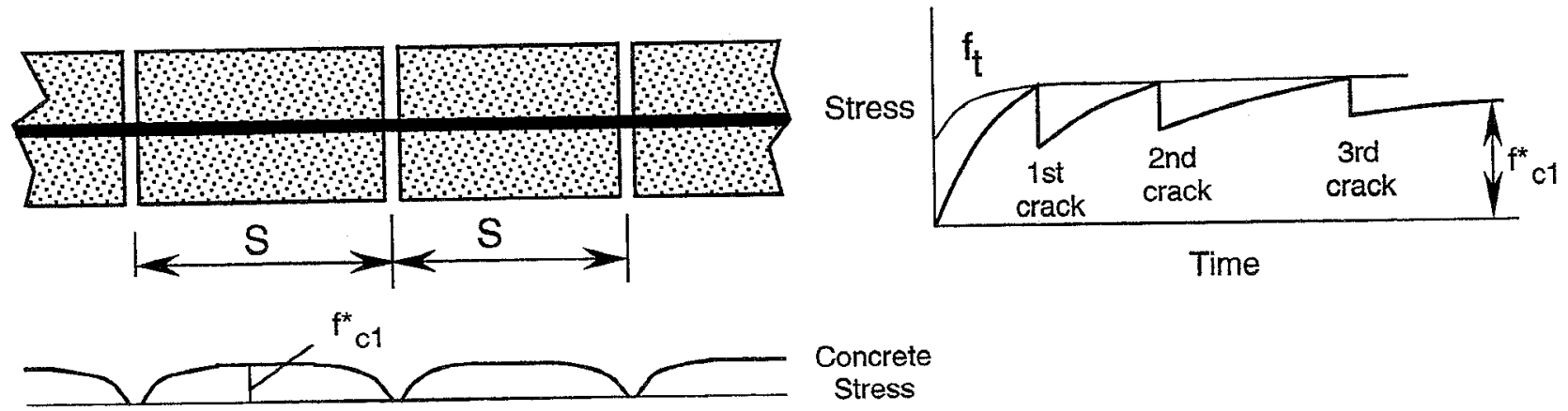

Concrete

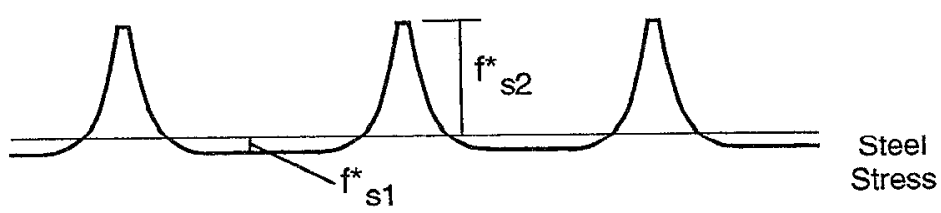

Figure 4.7 - Crack development due to restrained drying shrinkage (adapted from Gilbert 1992). 

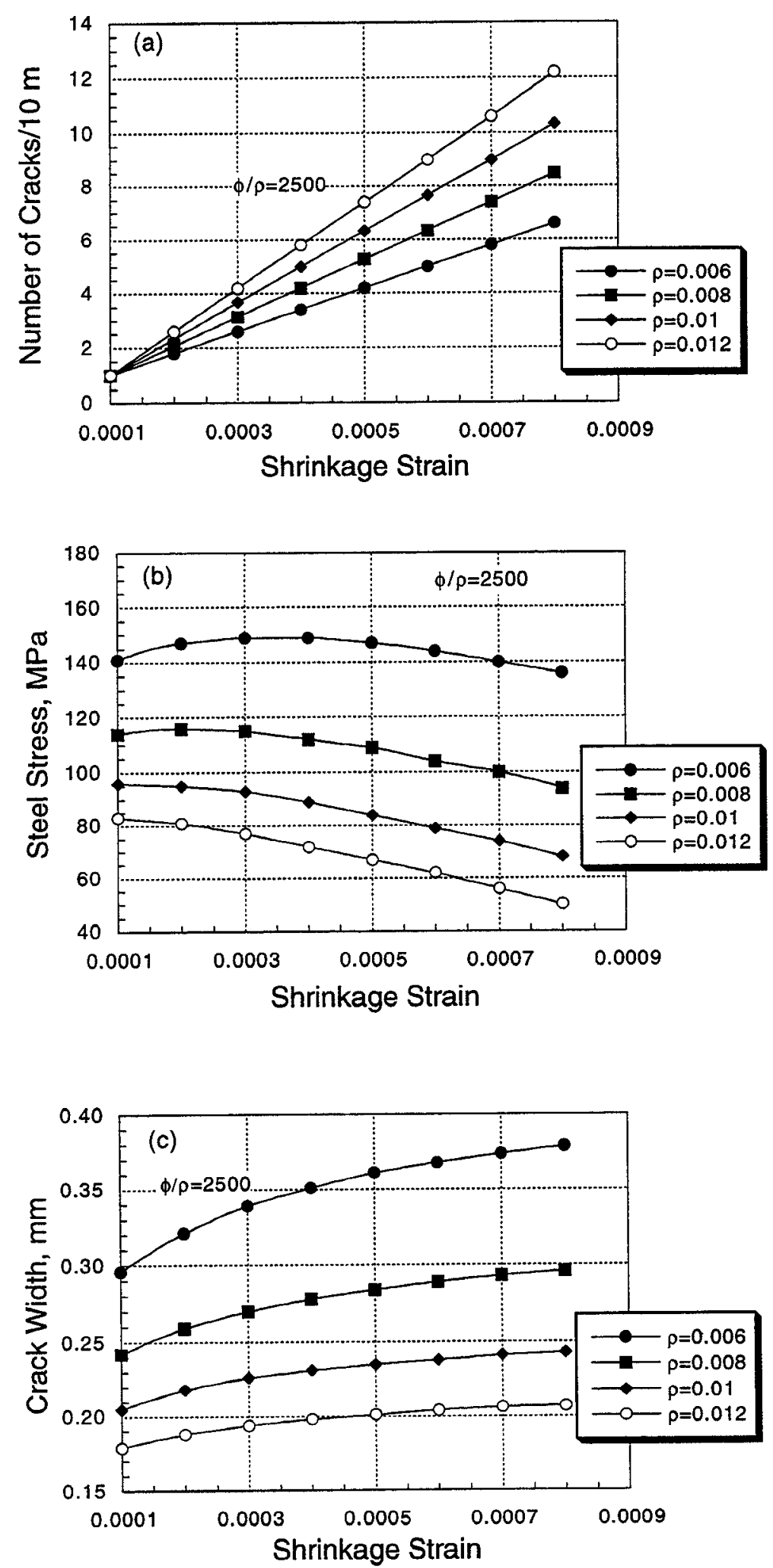

Figure 4.8 - Predicted cracking due to restrained shrinkage for 10-m long member according to method of Base and Murray (1982): (a) number of cracks, (b) steel stress at crack, and (c) average crack width. 

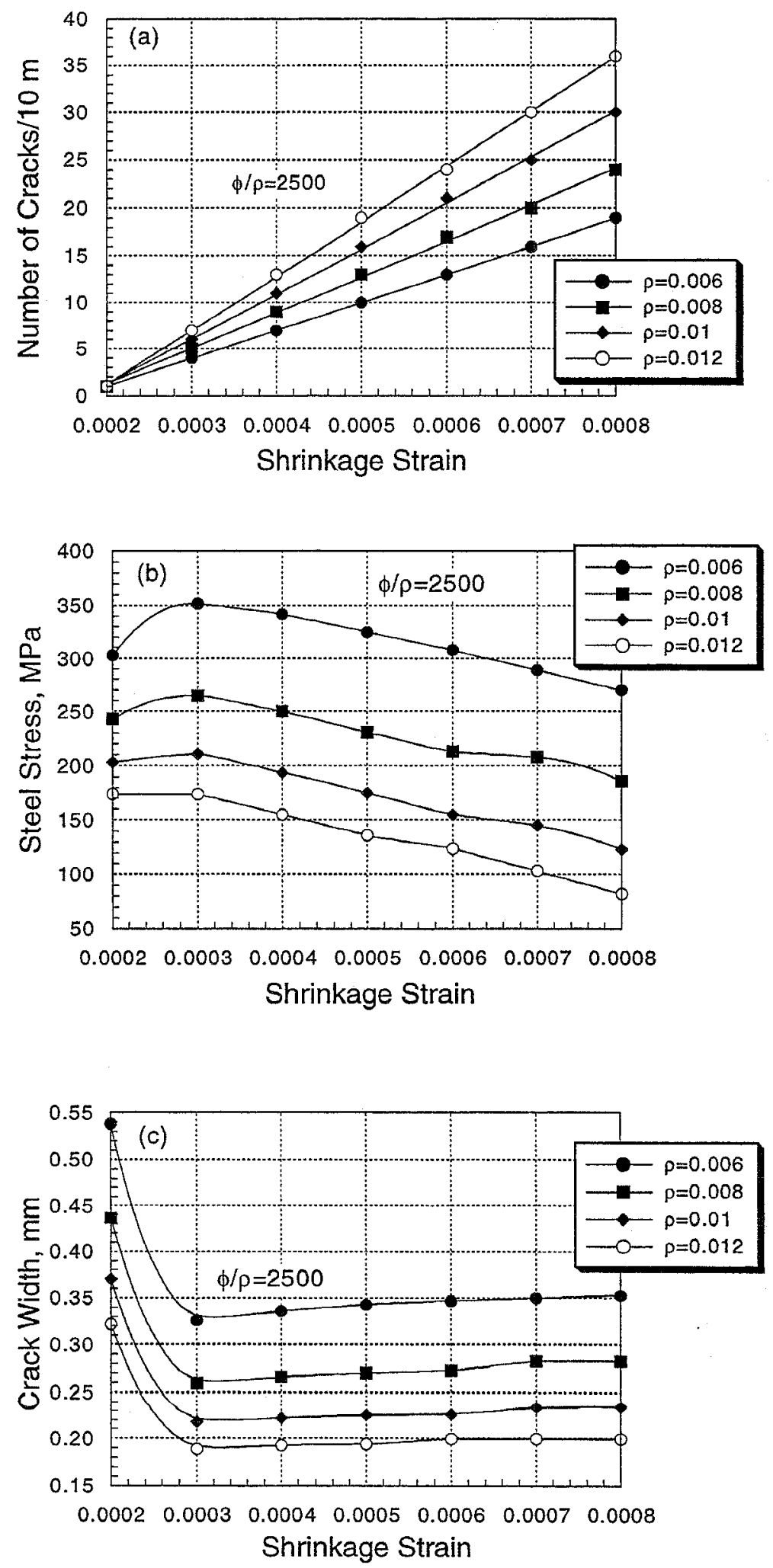

Figure 4.9 - Predicted cracking due to restrained shrinkage for 10- $\mathrm{m}$ long member according to method of Gilbert (1992): (a) number of cracks, (b) steel stress at crack, and (c) average crack width. 

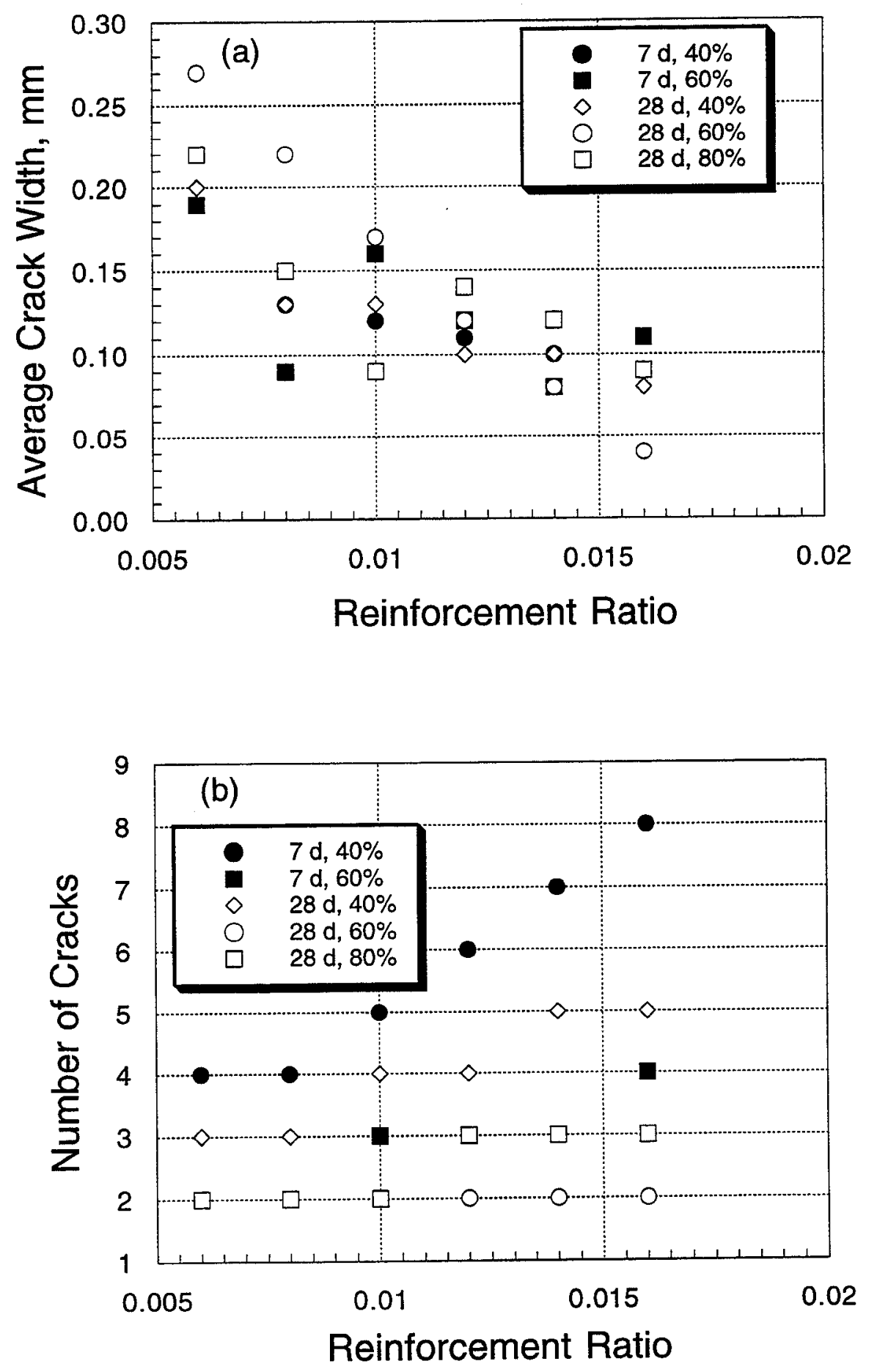

Figure 4.10 (a) Average crack width and (b) number of cracks for $0.76-\mathrm{m}$ thick, $7.3 \mathrm{~m}$ long slab restrained along two edges and exposed to same conditions as in Fig. $4.6\left(\mathrm{~S}_{0}=200\right.$ $\mathrm{mm}, 27.6 \mathrm{MPa}$ compressive strength). 


\section{SUMMARY}

\subsection{Reinforced Concrete Behavior}

Reinforced concrete members are designed under the assumption that the concrete has zero tensile strength. Steel reinforcement is provided to carry the tensile stresses needed to resist the applied loads. The ultimate strength design method is based on the concept that the member will reach its ultimate capacity under a loading condition that has a very low probability of being exceeded during the structure's lifetime. This provides a margin of safety against failure under service loads.

In an ordinary, properly designed, reinforced concrete structure it is expected that service loads will produce tensile stresses that exceed the strength of plain concrete and result in cracking. To assure that cracks will not impair the serviceability of a structure, the designer first proportions the members for adequate safety and then investigates the suitability of crack widths and deflections under service loads. In some situations, the need to satisfy stringent serviceability criteria, rather than assurance of adequate strength, may control the final design.

\subsection{Flexural Cracking}

Members, such as beams and slabs, which are subjected to bending moments will develop flexural cracks when the stresses in the tension zone exceed the bending strength of plain concrete. For practical purposes it can be assumed that the cracks will extend from the tension face to the location of the neutral axis of the cross section.

The most important factor controlling flexural crack width under a given load is the magnitude of the tensile strain in the reinforcing steel. Control of steel strain is the most effective means to limit crack widths in structures where limited widths are necessary to perform the intended function. Other important factors affecting crack widths are the concrete cover over the reinforcing steel, size of bars, and the distribution of the steel in the tension zone.

It is difficult to predict the number and width of flexural cracks because of the complex processes that are involved. As result there is no universal approach for estimating these quantities, and various design codes use different techniques. Some of these are based on regression analyses of test data and others are based on simplified models of the mechanics of crack formation. The predictions that result from these models are accompanied by an inherently high uncertainty. These methods are for predicting crack widths under short-term loading. Under sustained loads, crack widths increase with time.

\subsection{Shrinkage Cracking}

Shrinkage of concrete due to drying and thermal contraction can lead to cracking if a member is constructed so that there is restraint to the shrinkage. Restraint to shrinkage induces tensile 
stresses that can lead to cracks if the stresses exceed the tensile strength of the concrete. Drying shrinkage occurs gradually and the stresses induced by restraint are affected by the simultaneous processes of shrinkage, creep, and stress relaxation. In addition, the tensile strength and elastic modulus of the concrete also change with time.

The potential drying shrinkage of a concrete member is dependent on its geometry, the composition of the concrete, the length of the curing period, and the ambient relative humidity. Because of these factors, it is difficult to predict the induced tensile stresses due to restrained shrinkage. An example has been presented to show how the methods proposed by ACI Committee 209 can be used to predict the effects of the ambient relative humidity and the duration of the curing period on whether cracking will occur in a fully restrained member. The example illustrated the interdependence between curing age and the level of induced tensile stresses.

Because of the complexities involved in predicting drying shrinkage cracking, the ACI Code prescribes a minimum quantity of temperature and shrinkage steel to provide for control of crack widths. It was emphasized that the use of steel reinforcement will not eliminate shrinkage cracking but it will control crack widths. Techniques are available to permit the designer to exercise control over the widths of shrinkage-induced cracks. Two of these methods have been compared in this report. It was shown that they result in similar relationships between crack width and amount of reinforcement, but they differ in the number of predicted cracks. It is noted that cracking can be reduced not only by providing reinforcement, but also by using design details that reduce restraint of drying shrinkage.

Cracks due to restrained drying shrinkage can be serious because, unlike flexural cracks, they can extend through the full depth of a member. The report discussed the interaction of flexural cracks and restrained drying shrinkage cracks. It was explained that the consequence of drying shrinkage cracking in flexural members depends on the sequence of cracking and the details of the flexural reinforcement. In the most favorable situation, drying shrinkage leads simply to on increase in deflections, but in the most unfavorable situation full-depth cracks can form. The designer needs to consider these interactions to avoid undesirable full-depth cracks in critical structures, such as the containment for low level nuclear waste. 


\section{ACKNOWLEDGEMENTS}

The authors express their gratitude to Dr. Andrew W. Taylor of the Structures Division at NIST for his careful review of the manuscript and for his constructive comments. Gratitude is also extended to Dr. Randall W. Poston, Vice President of KCI Technologies Inc. and current Chairman of ACI Committee 224, for providing and expert review of this report. Finally, the authors acknowledge the guidance provided by Mr. Jacob Philip of the Nuclear Regulatory Commission, who served as the Program Manager for the project. 


\section{REFERENCES}

ACI 224R-90, "Control of Cracking in Concrete Structures," ACI Manual of Concrete Practice, Part 3, American Concrete Institute, Detroit, MI, 1992.

ACI 318-89, "Building Code Requirements for Reinforced Concrete," ACI Manual of Concrete Practice, Part 3, American Concrete Institute, Detroit, MI, 1992.

ACI 350R-89, "Environmental Engineering Concrete Structures," ACI Manual of Concrete Practice, Part 4, American Concrete Institute, Detroit, MI, 1992.

ACI 209R-82 (reapproved 1986), "Prediction of Creep, Shrinkage, and Temperature Effects in Concrete Structures," ACI Manual of Concrete Practice, Part 1, American Concrete Institute, Detroit, MI, 1992.

Base, G.D. and Murray, M.H., "A New Look at Shrinkage Cracking," Civil Engineering Transactions, The Institution of Engineers, Australia, Vol. CE 24, No.2, 1982, pp. 171-176.

Base, G.D., "Control of Flexural Cracking in Reinforced Concrete," Civil Engineering Transactions, The Institution of Engineers, Australia, Vol. CE 18, No.1, 1976, pp. 20-23.

Bazant, Z.P., "Prediction of Concrete Creep Effects Using Age-Adjusted Effective Modulus Method," ACI Journal, Vol. 69, No. 4, April 1972, pp. 212-216.

Beeby, A.W., "The Prediction of Crack Widths in Hardened Concrete," The Structural Engineer (UK), Vol. 57A, No. 1, January 1979, pp. 9-17.

"CEB/FIP Model Code 1990 - Final Draft, Chapters 4 -10," Information Bulletin 204, Comite EuroInternational du Beton, Lausanne, Switzerland

Gilbert, R. I., "Shrinkage Cracking in Fully Restrained Concrete Members," ACI Structural Journal, Vol. 89, No. 2, March-April 1992, pp. 141-149.

Hughes, B.P. and Cifuentes, C.V., "Comparison of Early-age Crack Width Formulas for Reinforced Concrete," ACI Structural Journal, Vol. 85, No. 2, March-April 1988, pp. 158-166.

Klein, F., Hoffman, E.S., and Rice, P.F., "Application of Strength Design Methods to Sanitary Structures," Concrete International, Vol. 3, No. 4, April 1982, pp. 35-40.

König, G. and Tue, N., "Crack Width Control for Concrete Constructions," Darmstadt Concrete, Vol. 7, 1992, pp. 231-245.

Shuman, R. et al., "Performance Assessment for Low-Level Waste Disposal Facilities," Electric Power Research Institute, EPRI NP-5745S, Interim Report, April 1988. 
Tam, K.S.S. and Scanlon, A., "Analysis of Cracking Due to Restrained Volume Change in Reinforced Concrete Members," ACI Journal, Vol. 83, No. 4, July-August 1986a, pp. 658-667.

Tam, K.S.S. and Scanlon, A., "Deflection of Two-Way Slabs Subjected to Restrained Volume Change and Transverse Loads," ACI Journal, Vol. 83, No. 5, September-October, 1986b, pp. 737-744.

Timoshenko, S.P. and Gere, J.M., Mechanics of Materials, D. Van Nostrand Co., New York, 1972.

Winter, G. and Nilson, A.H., Design of Concrete Structures, 9th Ed., McGraw-Hill Book Co., New York, 1979 